\title{
Stochastic study of relativistic lutetium nanoparticles moving in a quantum field of synchrotron radiation emission when charged lutetium nanoparticles are accelerated radially in human cancer cells, tissues and tumors treatment
}

\author{
Heidari $\mathrm{A}^{1,2^{*}}$, Schmitt $\mathrm{K}^{1}$, Henderson $\mathrm{M}^{1}$ and Besana $\mathrm{E}^{1}$ \\ ${ }^{1}$ Faculty of Chemistry, California South University, 14731 Comet St. Irvine, CA 92604, USA \\ ${ }^{2}$ American International Standards Institute, Irvine, CA 3800, USA
}

\begin{abstract}
In the current study, thermoplasmonic characteristics of Lutetium nanoparticles with spherical, core-shell and rod shapes are investigated. In order to investigate these characteristics, interaction of synchrotron radiation emission as a function of the beam energy and Lutetium nanoparticles were simulated using 3D finite element method. Firstly, absorption and extinction cross sections were calculated. Then, increases in temperature due to synchrotron radiation emission as a function of the beam energy absorption were calculated in Lutetium nanoparticles by solving heat equation. The obtained results show that Lutetium nanorods are more appropriate option for using in optothermal human cancer cells, tissues and tumors treatment method.
\end{abstract}

\section{Introduction}

In recent decade, metallic nanoparticles have been widely interested due to their interesting optical characteristics [1-8]. Resonances of surface Plasmon in these nanoparticles lead to increase in synchrotron radiation emission as a function of the beam energy scattering and absorption in related frequency $[9,10]$. Synchrotron radiation emission as a function of the beam energy absorption and induced produced heat in nanoparticles has been considered as a side effect in plasmonic applications for a long time [11-15]. Recently, scientists find that thermoplasmonic characteristic can be used for various optothermal applications in cancer, nanoflows and photonic [16-22]. In optothermal human cancer cells, tissues and tumors treatment, the descendent laser light stimulate resonance of surface Plasmon of metallic nanoparticles and as a result of this process, the absorbed energy of descendent light converse to heat in nanoparticles [23-25]. The produced heat devastates tumor tissue adjacent to nanoparticles without any hurt to sound tissues $[26,27]$. Regarding the simplicity of ligands connection to Lutetium nanoparticles for targeting cancer cells, these nanoparticles are more appropriate to use in optothermal human cancer cells, tissues and tumors treatment [28-74]. In the current paper, thermoplasmonic characteristics of spherical, core-shell and rod Lutetium nanoparticles are investigated.

Heat generation in synchrotron radiation emission as a function of the beam energy-lutetium nanoparticles interaction

When Lutetium nanoparticles are subjected to descendent light, a part of light scattered (emission process) and the other part absorbed (non-emission process). The amount of energy dissipation in non-emission process mainly depends on material and volume of nanoparticles and it can be identified by absorption cross section. At the other hand, emission process which its characteristics are depend on volume, shape and surface characteristics of nanoparticles explains by scattering cross section. Sum of absorption and scattering processes which lead to light dissipation is called extinction cross section [75123].

Lutetium nanoparticles absorb energy of descendent light and generate some heat in the particle. The generated heat transferred to the surrounding environment and leads to increase in temperature of adjacent points to nanoparticles. Heat variations can be obtained by heat transfer equation [124-202].

\section{Simulation}

To calculate the generated heat in Lutetium nanoparticles, COMSOL software which works by Finite Element Method (FEM)

${ }^{*}$ Correspondence to: Heidari A, Faculty of Chemistry, California South University, 14731 Comet St. Irvine, CA 92604, USA and American International Standards Institute, Irvine, CA 3800, USA, E-Mail: Alireza.Heidari@calsu.us

Key words: lutetium nanoparticles, scanning electron microscope (SEM), 3D finite element method (FEM), heat transfer equation, optothermal, heat distribution, thermoplasmonic, lutetium nanorods, human cancer cells, tissues and tumors treatment, simulation, synchrotron radiation, emission, function, beam energy

Received: December 26, 2019; Accepted: January 09, 2020; Published: January 13,2020 
Heidari A (2020) Stochastic study of relativistic lutetium nanoparticles moving in a quantum field of synchrotron radiation emission when charged lutetium nanoparticles are accelerated radially in human cancer cells, tissues and tumors treatment

was used. All simulations were made in 3D. Firstly, absorption and scattering cross section areas were calculated by optical module of software. Then, using heat module, temperature variations of nanoparticles and its surrounding environment were calculated by data from optical module [203-283]. In all cases, Lutetium nanoparticles are presented in water environment with dispersion coefficient of 1.84 and are subjected to flat wave emission with linear polarization. Intensity of descendent light is $1 \mathrm{~mW} / \mu \mathrm{m} 2$. Dielectric constant of Lutetium is dependent on particle size [284-414].

Firstly, calculations were made for Lutetium nanospheres with radius of $5,10,15,20,25,30,35,40,45$ and 50 nanometers. The results show that by increase in nanoparticles size, extinction cross section area increases and maximum wavelength slightly shifts toward longer wavelengths. The maximum increase in temperature of nanospheres in surface Plasmon frequency is shown in Figure 1.

According to the graph, it can be seen that the generated heat is increased by increase in nanoparticles size. For $100 \mathrm{~nm}$ nanoparticles (sphere with $50 \mathrm{~nm}$ radius), the maximum increase in temperature is 83 $\mathrm{K}$. When nanoparticles size reaches to $150 \mathrm{~nm}$, increase in temperature is increased in spite of increase in extinction coefficient. In order to find the reason of this fact, ratio of absorption to extinction for various nanospheres in Plasmon frequency is shown in Figure 2.

Figure 2 shows that increasing the size of nanospheres leads to decrease in ratio of light absorption to total energy of descendent light so that for $150 \mathrm{~nm}$ nanosphere, scattering is larger than absorption. It seems that although increase in nanoparticles size leads to more dissipation of descendent light, the dissipation is in the form of scattering and hence, it cannot be effective on heat generation.

Heat distribution (Figure 3) shows that temperature is uniformly distributed throughout the nanoparticles which are due to high thermal conductivity of Lutetium.

In this section, core-shell structure of Lutetium and silica is chosen. The core of a nanosphere with $45 \mathrm{~nm}$ radius and silica layer thickness of $5,10,15,20,25,30,35,40,45$ and 50 nanometers are considered. The results show that increase in silica thickness leads to increase in extinction coefficient and shift in Plasmon wavelength of nanoparticles, to some extent.

According to Figure 4, silica shell causes to considerable increase in temperature of Lutetium nanoparticles but by more increase in

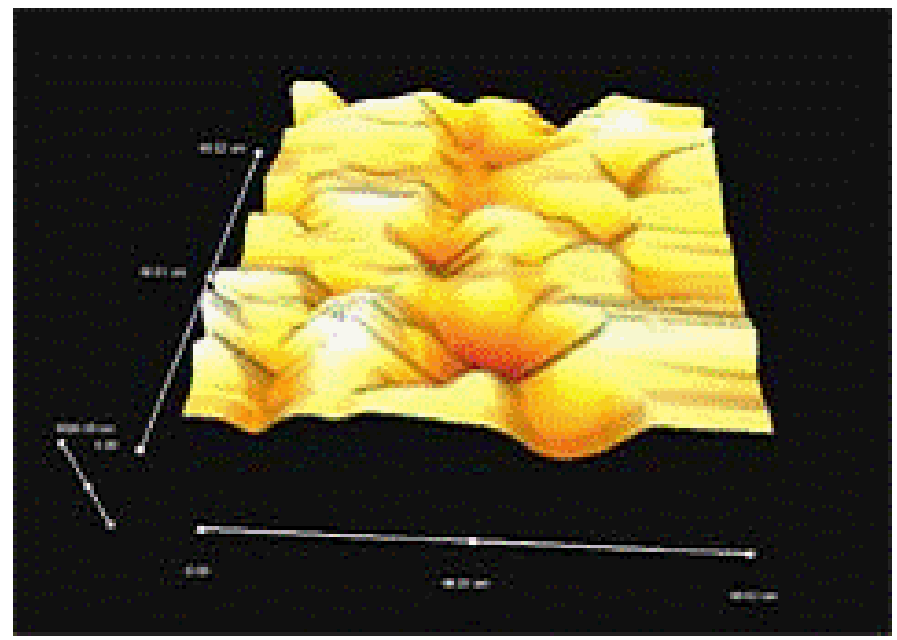

Figure 1. Maximum increase in temperature for Lutetium nanospheres

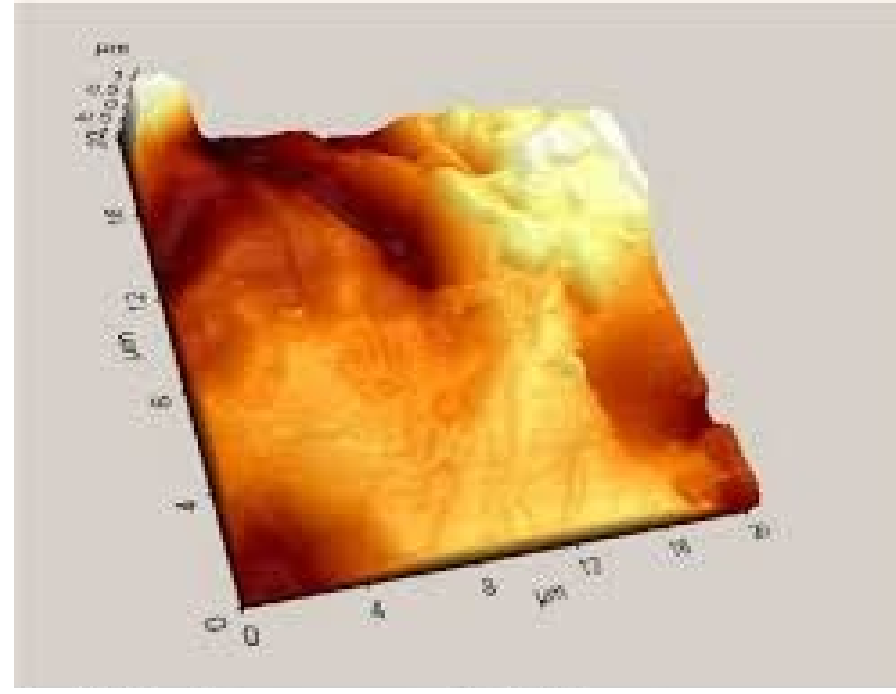

Figure 2. Variations of absorption to extinction ratio and scattering to extinction ratio for Lutetium nanospheres with various radiuses

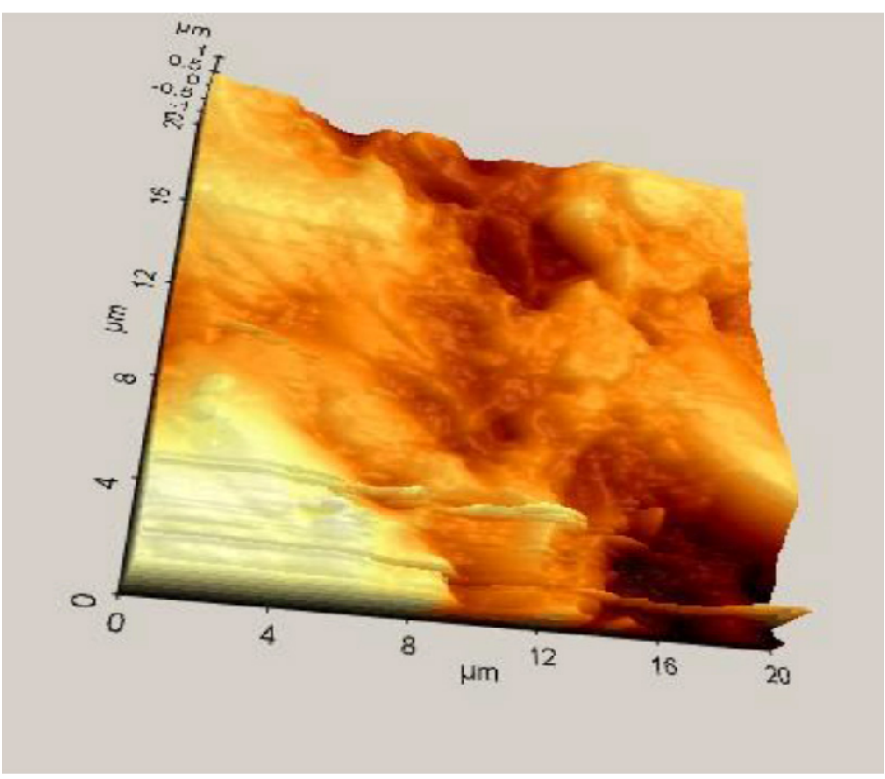

Figure 3. Maximum increase in temperature for spherical nanoparticles with radius of 45 $(\mathrm{nm})$ at Plasmon wavelength of $685(\mathrm{~nm})$

silica thickness, its effects are decreased. Heat distribution (Figure 5) shows that temperature is uniformly distributed throughout metallic core as well as silica shell. However, silica temperature is considerably lower than core temperature due to its lower thermal conductivity. In fact, silica layer prohibits heat transfer from metal to the surrounding aqueous environment due to low thermal conductivity and hence, temperature of nanoparticles has more increase in temperature. Increasing the thickness of silica shell leads to increase in its thermal conductivity and hence, leads to attenuate in increase in nanoparticles temperature.

Figure 6 is drawn. This graph shows that variation of nanorod dimension ratio leads to considerable shift in Plasmon wavelength. This fact allows regulating the Plasmon frequency to place in near IR zone. Light absorption by body tissues is lower in this zone of spectrum and hence, nanorods are more appropriate for optothermal human cancer cells, tissues and tumors treatment methods. 
Heidari A (2020) Stochastic study of relativistic lutetium nanoparticles moving in a quantum field of synchrotron radiation emission when charged lutetium nanoparticles are accelerated radially in human cancer cells, tissues and tumors treatment

Variations of temperature in Lutetium nanorods with two effective radius and various dimension ratios are shown in Figure 7. By increase in length (a) to radius (b) of nanorod, temperature is increased.

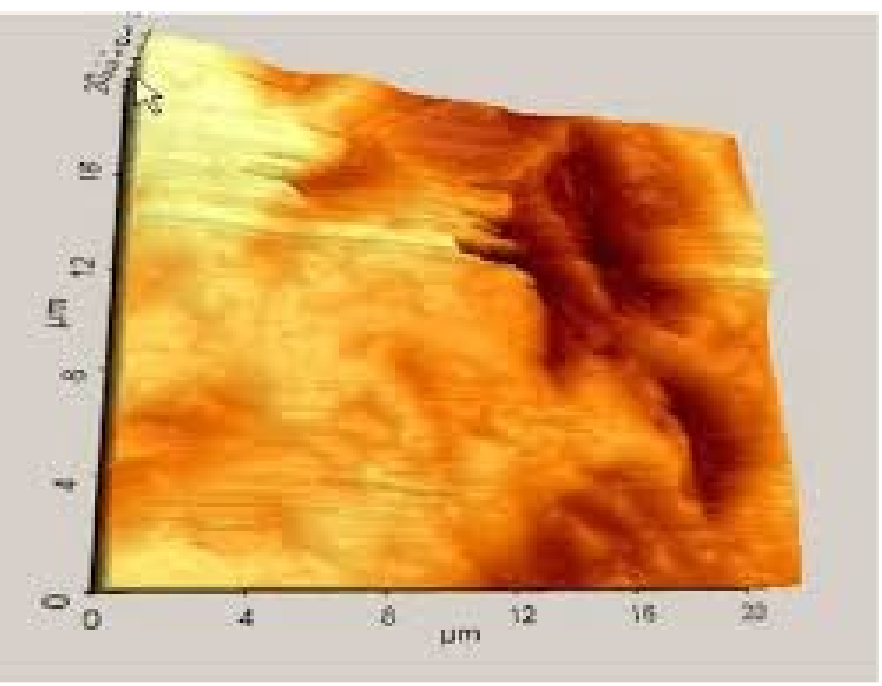

Figure 4. Maximum increase in temperature for core-shell Lutetium nanospheres with various thicknesses of silica shell

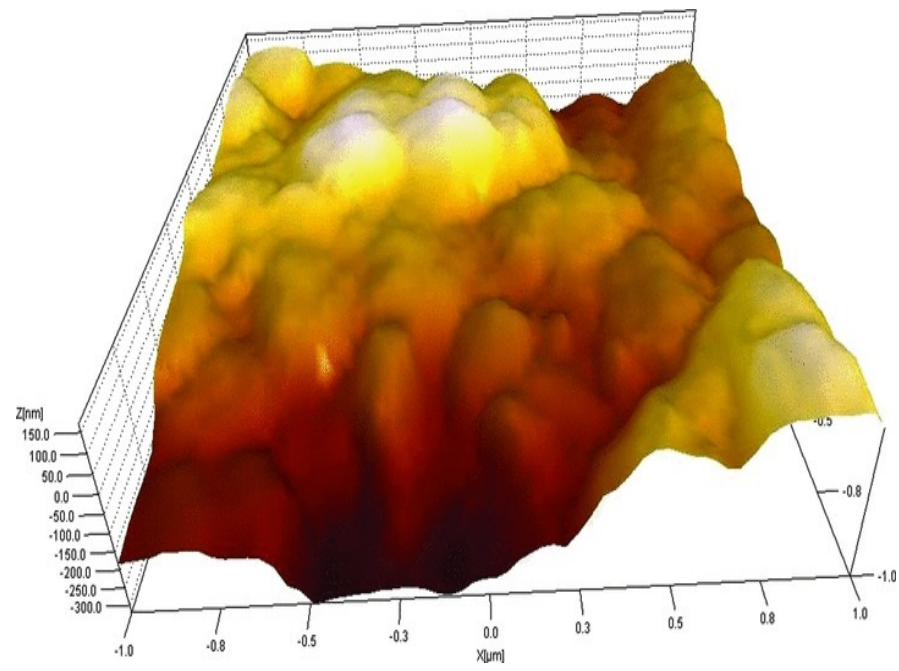

Figure 5. Maximum increase in temperature for core-shell nanoparticles with radius of 45 $(\mathrm{nm})$ and silica thickness of $10(\mathrm{~nm})$ at Plasmon wavelength of $701(\mathrm{~nm})$

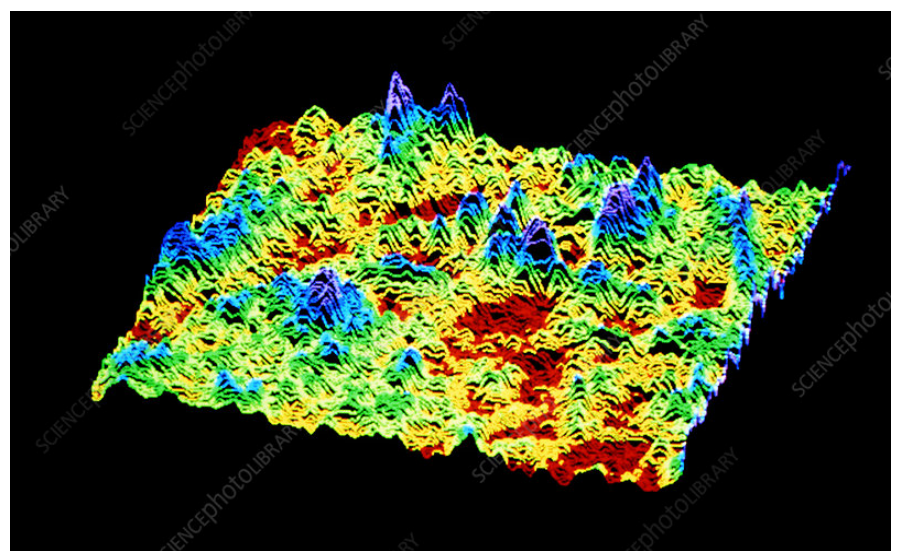

Figure 6. Extinction cross section area for Lutetium nanorods with effective radius of 45 $(\mathrm{nm})$ and various dimension ratios

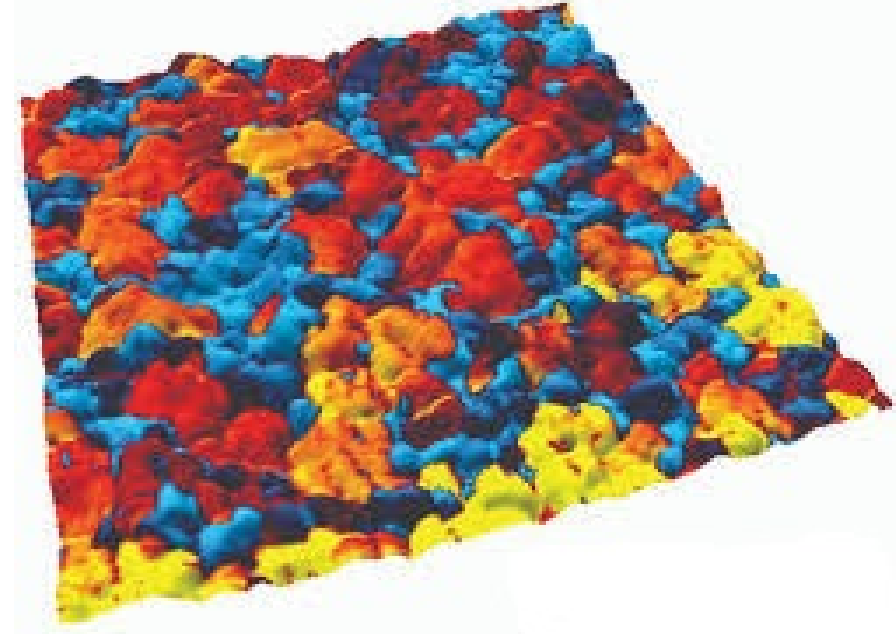

Figure 7. Maximum increase in temperature for nanorods with effective radius of 20 and 45 $(\mathrm{nm})$ and various dimension ratios

\section{Conclusion and summary}

The calculations showed that in Lutetium nanoparticles, light absorption in Plasmon frequency causes to increase in temperature of the surrounding environment of nanoparticles. In addition, it showed that adding a thin silica layer around the Lutetium nanospheres increases their temperatures. Calculations of nanorods showed that due to ability for shifting surface Plasmon frequency toward longer wavelength as well as more increase in temperature, this nanostructure is more appropriate for medical applications such as optothermal human cancer cells, tissues and tumors treatments.

\section{Acknowledgements}

Authors are supported by an American International Standards Institute (AISI) Future Fellowship Grant FT12010093734715. We acknowledge Ms. Isabelle Villena for instrumental support and Dr. Michael N. Cocchi for constructing graphical abstract figures. We gratefully acknowledge Prof. Dr. Christopher Brown for proof reading the manuscript. Synchrotron beam time was awarded by the National Synchrotron Light Source (NSLS-II) under the merit-based proposal scheme.

\section{References}

1. Yu P (2016) Design and fabrication of silicon nanowires towards efficient solar cells Nano Today 11: 704-737.

2. Sandhu S, Fan S (2015) Current-voltage enhancement of a single coaxial nanowire solar cell. ACS Photonics 2: 1698-1704.

3. van Dam D, Van Hoof M (2016) High-efficiency nanowire solar cells with omnidirectionally enhanced absorption due to self-aligned indium-tin-oxide mie scatterers. ACS Nano 10.

4. Luo S, He Y (2015) Size-dependent optical absorption modulation of si/ge and ge/ si core/shell nanowires with different cross-sectional geometries. Nanotechnology 26 085702 .

5. Yu P, Yao Y (2017) Effects of plasmonic metal core-dielectric shell nanoparticles on the broadband light absorption enhancement in thin film solar cells. Sci Rep 7: 7696.

6. Gouda AM, Allam NK (2017) Efficient fabrication methodology of wide angle black silicon for energy harvesting applications. RSC Adv 7: 26974-26982.

7. Branz HM (2009) Nanostructured black silicon and the optical reflectance of gradeddensity surfaces. Appl Phys Lett 94: 231121

8. Fazio B, Artoni (2016) Strongly enhanced light trapping in a two-dimensional silicon nanowire random fractal array. Light Sci Appl 5: e16062. 
Heidari A (2020) Stochastic study of relativistic lutetium nanoparticles moving in a quantum field of synchrotron radiation emission when charged lutetium nanoparticles are accelerated radially in human cancer cells, tissues and tumors treatment

9. Ko MD (2015) High efficiency silicon solar cell based on asymmetric nanowire. Sci Rep 5: 11646.

10. Oh J (2012) An 18.2\%-Efficient black-silicon solar cell achieved through control of carrier recombination in nanostructures. Nat Nanotechnol 7: 743-748.

11. Lin H (2014) Rational design of inverted nanopencil arrays for cost-effective, broadband, and omnidirectional light harvesting. ACS Nano 8: 3752-3760.

12. Garnett E (2010) Light trapping in silicon nanowire solar cells. Nano Lett 10: 1082 1087.

13. Misra S, Yu L (2013) High efficiency and stable hydrogenated amorphous silicon radial junction solar cells built on vls-grown silicon nanowires. Sol Energy Mater Sol Cells 118: 90-95.

14. Kelzenberg MD (2010) Enhanced absorption and carrier collection in si wire arrays for photovoltaic applications. Nat Mater 9: 239-244.

15. Tian B (2007) Coaxial silicon nanowires as solar cells and nanoelectronic power sources. Nature 449: 885-889.

16. Razek SA (2014) Vertically aligned crystalline silicon nanowires with controlled diameters for energy conversion applications: Experimental and theoretical insights. Journal Applied Physics 115: 194305

17. Dhindsa Nia (2016) A Platform for colorful solar cells with enhanced absorption. Nanotechnology 27: 495203.

18. Dhindsa N, Walia J (2016) Adjustable optical response of amorphous silicon nanowires integrated with thin films. Nanotechnology 27: 145703.

19. Zhu J (2009) Optical Absorption enhancement in amorphous silicon nanowire and nanocone arrays. Nano Lett 9: 279-282.

20. Klinger D (2006) Nano-structure formed by nanosecond laser annealing on amorphous si surface. Mater Sci Semicond Process 9: 323-326.

21. Kumar P ()2009 Excimer laser induced nanostructuring of silicon surfaces. Journal NanoSci Nanotechnol 9: 3224-3232.

22. Kumar P (2010) Surface modulation of silicon surface by excimer laser at laser fluence below ablation threshold. Appl Phys A Mater Sci Process 99: 245-250.

23. Adikaari AADT (2005) Thickness dependence of properties of excimer laser crystallized nano-polycrystalline silicon. Journal Applied Physics 97: 114305.

24. Adikaari AADT (2007) Efficient laser textured nanocrystalline silicon-polymer bilayer solar cells. Appl Phys Lett 90: 203514.

25. Adikaari AADT (2008) Excimer laser crystallization and nanostructuring of amorphous silicon for photovoltaic applications. Nano 3: 117-126.

26. Tang YF (2002) Electron field emission from excimer laser crystallized amorphous silicon. Appl Phys Lett 80: 4154-4156.

27. Jin S (2016) Low temperature polycrystalline silicon with single orientation on glass by blue laser annealing. Thin Solid Films 616: 838-841.

28. Crouch CH (2004) Comparison of structure and properties of femtosecond and nanosecond laser-structured silicon. Appl Phys Lett 84: 1850-1852.

29. Wu C (2001) Near-unity below-band-gap absorption by microstructured silicon. Appl Phys Lett 78: 1850-1852.

30. Pedraza AJ, Fowlkes JD (1999) Silicon microcolumn arrays grown by nanosecond pulsed-excimer laser irradiation. Appl Phys Lett 74: 2322.

31. Pedraza AJ (2000) Surface micro-structuring of silicon by excimer-laser irradiation in reactive atmospheres. App Surf Sci 168: 251-257.

32. Porte HP, Turchinovich D (2013) On ultrafast photoconductivity dynamics and crystallinity of black silicon. IEEE Trans Terahertz Sci Technol 3: 331-341.

33. Georgiev DG (2004) Controllable excimer-laser fabrication of conical nano-tips on silicon thin films. Appl Phys Lett 84: 4881-4883.

34. Eizenkop J (2008) Single-pulse excimer laser nanostructuring of silicon: a heat transfer problem and surface morphology. Journal Applied Physics 103: 094311.

35. Eizenkop J (2007) Single pulse excimer laser nanostructuring of thin silicon films: nanosharp cones formation and a heat transfer problem. Journal Applied Physics 101: 094301.

36. Hong L (2013) RusliFemtosecond laser induced nanocone structure and simultaneous crystallization of $1.6 \mu \mathrm{M}$ amorphous silicon thin film for photovoltaic application. Journal Phys Appl Phys 46: 195109.
37. Hong L (2012) Crystallization and surface texturing of amorphous-Si induced by UV laser for photovoltaic application. Journal Applied Physics 111: 043106.

38. Magdi S (2017) Broadband absorption enhancement in amorphous si solar cells using metal gratings and surface texturing. Proc SPIE 10099.

39. Diedenhofen SL (2011) Strong geometrical dependence of the absorption of light in arrays of semiconductor nanowires. ACS Nano 5: 2316-2323.

40. Jäger ST (2014) Design parameters for enhanced photon absorption in vertically aligned silicon nanowire arrays. Nanoscale Res Lett 9: 511.

41. Gouda AM (2016) Lithography-free wide-angle antireflective self-cleaning silicon nanocones. Opt Lett 41: 3575

42. Magdi S, Swillam MA (2017) Optical analysis of si-tapered nanowires/low band gap polymer hybrid solar cells. Proc SPIE 10099.

43. Jiang Y (2016) Efficiency enhancement mechanism for Poly(3, 4-ethylenedioxythioph ene):Poly(styrenesulfonate)/silicon nanowires hybrid solar cells using alkali treatment. Nanoscale Res Lett 11: 267.

44. Gong X, Jiang Y, Li M (2015) Hybrid tapered silicon nanowire/PEDOT:PSS Solar Cells. RSC Adv 5: 10310-10317.

45. Mohammad NS (2014) Understanding quantum confinement in nanowires: basics, applications and possible laws. Journal Phys Condens Matter 26: 423202.

46. Zhang A, Luo S, Ouyang G, Yang G (2013) W.Strain-Induced optical absorption properties of semiconductor nanocrystals. Journal Chem Phys 138: 244702.

47. He Y (2016) Shape-dependent conversion efficiency of si nanowire solar cells with polygonal cross-sections. Journal Applied Physics 119: 225101.

48. Tchakarov S (2004) Helium versus hydrogen dilution in the optimization of polymorphous silicon solar cells. Journal Non-Cryst Solids 338: 668-672.

49. Roszairi H (2002) High deposition rate thin film hydrogenated amorphous silicon prepared by d.c. plasma enhanced chemical vapour deposition of helium diluted silane. IEEE International Conference on Semiconductor Electronics, 2002. Proceedings. ICSE Panang, Malaysia. Dec. 19-21.

50. N'Guyen (2013) Functional iron oxide magnetic nanoparticles with hyperthermiainduced drug release ability by using a combination of orthogonal click reactions. Angew Chem Int Ed 52: 14152-14156.

51. Xu Z (2013) Thermally Healable Polyhedral Oligomeric Silsesquioxane (POSS) Nanocomposite based on Diels-Alder chemistry. Chem Commun 2: 14152-14156.

52. Engel T (2014) Self-healing nanocomposites from silica - polymer core - shell nanoparticles. Polym Int 63: 915-923.

53. Engel T (2015) Furan-Modified Spherosilicates as Building Blocks for Self-Healing Materials. Eur Joruanl Inorg Chem 4: 1226-1232.

54. Torres-Lugo M (2013) Thermal potentiation of chemotherapy by magnetic nanoparticles. Nanomedicine 8: 1689-1707.

55. Hohlbein N (2015) Self-healing dynamic bond-based rubbers: understanding the mechanisms in ionomeric elastomer model systems. Phys Chem 17: 21005-21017.

56. Wu CS (2012) Preparation of Polybenzoxazine-functionalized Fe3O4 nanoparticles through in situ diels-alder polymerization for high performance magnetic polybenzoxazine/Fe3O4 Nanocomposites. Compos Sci Technol 72: 1562-1567.

57. Menon AV (2018) Ultrafast self-healable interfaces in polyurethane nanocomposites designed using diels-alder "click" as an efficient microwave absorber. ACS Omega 3 : 1137-1146

58. Engel T (2013) Thermoreversible reactions on inorganic nanoparticle surfaces: Dielsalder reactions on sterically crowded surfaces. Chem Mater 25: 149-157.

59. Schäfer S (2015) Kickelbick, G.self-healing polymer nanocomposites based on dielsalder-reactions with silica nanoparticles: The role of the polymer matrix. Polymer 69 : 357-368

60. Park JS (2010) Multiple healing effect of thermally activated self-healing composites based on diels-alder reaction. compos. Sci Technol 70: 2154-2159.

61. Li J (2014) Healable capacitive touch screen sensors based on transparent composite electrodescomprising silver nanowires and a furan/maleimide diels-alder cycloaddition polymer. ACS Nano 8: 12874-12882.

62. Sun S (2004) Monodisperse MFe2O4 (M = Fe, Co, Mn) Nanoparticles. J Am Chem Soc 126: 273-279. 
Heidari A (2020) Stochastic study of relativistic lutetium nanoparticles moving in a quantum field of synchrotron radiation emission when charged lutetium nanoparticles are accelerated radially in human cancer cells, tissues and tumors treatment

63. Frison R, Cernuto G, Cervellino A, Zaharko O, Colonna GM, et al. (2013) MagnetiteMaghemite Nanoparticles in the 5-15 nm Range: Correlating the Core-Shell Composition and the Surface Structure to the Magnetic Properties. A Total Scattering Study. Chem Mater 25: 4820-4827

64. Salazar SJ (2011) Iron Oxide Nanoparticles in 10-40 nm Range: Composition in Terms of Magnetite/Maghemite Ratio and Effect on the Magnetic Properties. Chem Mater 23: $1379-1386$

65. Guerrero G (2001) Anchoring of Phosphonate and Phosphinate Coupling Molecules on Titania Particles. Chem Mater 13: 4367-4373.

66. Babu K (2008) Grafting of Poly(methyl methacrylate) Brushes from Magnetite Nanoparticles Using a Phosphonic Acid Based Initiator by Ambient Temperature Atom Transfer Radical Polymerization (ATATRP). Nanoscale Res. Lett 3: 109-117.

67. Mohapatra S (2009) Synthesis and Stability of Functionalized Iron Oxide Nanoparticles using Organophosphorus Coupling Agents. Colloids Surf 339: 35-42.

68. Larsen BA (2012) Mono- and Dialkoxysilane Surface Modification of Superparamagnetic Iron Oxide Nanoparticles for Application as Magnetic Resonance Imaging Contrast Agents. Journal Mater Res 27: 1846-1852.

69. Davis K (2014) Quantitative measurement of ligand exchange on iron oxides via radiolabeled oleic acid. Langmuir 30: 10918-10925.

70. Feichtenschlager B (2012) Nanoparticle assemblies as probes for self-assembled monolayer characterization: correlation between surface functionalization and agglomeration behavior. Langmuir 28: 741-750.

71. Musa OM (2016) Handbook of maleic anhydride based materials: syntheses, properties and applications;springer international publishing: Switzerland 2: 175.

72. Sauer R (2012) Design, synthesis, and miniemulsion polymerization of new phosphonate surfmers and application studies of the resulting nanoparticles as model systems for biomimetic mineralization and cellular uptake. chem. Eur J 18: 5201-5212.

73. Lu C, Bhatt LR (2012) Carboxyl-Polyethylene Glycol-Phosphoric Acid: A ligand for highly stabilized iron oxide nanoparticles. J Mater Chem 22: 19806-19811.

74. Patsula V (2016) Superparamagnetic Fe3O4 Nanoparticles: Synthesis by thermal decomposition of iron(iii) glucuronate and application in magnetic resonance imaging. ACS Appl Mater Interfaces 8: 7238-7247.

75. Pothayee N, Balasubramaniam S (2011) Synthesis of 'ready-to-adsorb' Polymeric Nanoshells for Magnetic Iron Oxide Nanoparticles via Atom Transfer Radical Polymerization. Polymer 52: 1356-1366.

76. Daou J (2007) Phosphate adsorption properties of magnetite-based nanoparticles Chem Mater 19: 4494-4505.

77. Breucker L (2015) Phosphonic acid-functionalized polyurethane dispersions with improved adhesion properties. ACS Appl Mater Interfaces 7: 24641-24648.

78. Sahoo Y (2001) Alkyl Phosphonate/Phosphate coating on magnetite nanoparticles: a comparison with fatty acids. Langmuir 17: 7907-7911.

79. Longo RC (2013) Monolayer doping via phosphonic acid grafting on silicon: Microscopic insight from infrared spectroscopy and density functional theory calculations. Adv Funct Mater 23: 3471-3477.

80. Luschtinetz R (2007) Infrared spectra of alkylphosphonic acid bound to aluminium surfaces. macromol. Symp 254: 248-253.

81. Thomas LC (1964) Characteristic infrared absorption frequencies of organophosphorus compounds-II. P-O-(X) Bonds. Spectrochim Acta 20: 489-502.

82. Quinones R (2017) Study of perfluorophosphonic acid surface modifications on zinc oxide nanoparticles. Materials 10: 1-16.

83. Lalatonne Y (2008) Bis-Phosphonates-Ultra small superparamagnetic iron oxide nanoparticles: A platform towards diagnosis and therapy. Chem Commun 5: 2553-2555.

84. Jastrzebski W (2011) Infrared spectroscopy of different phosphates structures. Spectrochim Acta Part A 79: 722-727.

85. Brodard-Severac F (2008) High-Field 17O MAS NMR investigation of phosphonic acid monolayers on titania. Chem Mater 20: 5191-5196.

86. Brice-Profeta S (2005) Magnetic order in g-Fe2O3 nanoparticles: A XMCD Study. Journal Magn Mater 288: 354-365.

87. Tronc E, Ezzir A (2000) Surface-related properties of g-Fe2O3 nanoparticles. Journal Magn Mater 221: 63-79.

88. Yee C (1999) Self-assembled monolayers of alkanesulfonic and -phosphonic acids on amorphous iron oxide nanoparticles. Langmuir 15: 7111-7115.
89. Jolivet JP (2004) Iron oxide chemistry. from molecular clusters to extended solid networks. Chem Commun 5: 481-487.

90. Campbell VE (2016) Engineering the magnetic coupling and anisotropy at the molecule-magnetic surface interface in molecular spintronic devices. Nat Commun 7: 13646 .

91. Pabisiak T, Winiarski MJ (2016) Adsorption of gold subnano-structures on a magnetite (111) surface and their interaction with CO. Phys Chem 18: 18169-18179.

92. Gomes R (2011) Binding of phosphonic acids to cdse quantum dots: A solution NMR study. Journal Phys Chem Lett 2: 145-152.

93. Chun YJ (1984) Synthesis of $\omega$-Phthalimidoalkylphosphonates. Synthesis 4: 909-910.

94. Heidari C (2015) Study of composition and morphology of cadmium oxide (CdO) nanoparticles for eliminating cancer cells. J Nanomed Res 2: 20.

95. Heidari C (2016) Study of surface morphological, phytochemical and structural characteristics of rhodium (III) oxide (Rh2O3) nanoparticles. International Journal of Pharmacology, Phytochemistry and Ethnomedicine 1: 15-19.

96. Heidari (2016) An experimental biospectroscopic study on seminal plasma in determination of semen quality for evaluation of male infertility. Int $J$ Adv Technol 7: e007.

97. Heidari (2016) Extraction and Preconcentration of N-Tolyl-Sulfonyl-PhosphoramidSaeure-Dichlorid as an Anti-Cancer Drug from Plants: A Pharmacognosy Study. $J$ Pharmacogn Nat Prod 2: e103.

98. Heidari (2016) A Thermodynamic Study on Hydration and Dehydration of DNA and RNA-Amphiphile Complexes. J Bioeng Biomed Sci 5: 006.

99. Heidari (2016) Computational Studies on Molecular Structures and Carbonyl and Ketene Groups' Effects of Singlet and Triplet Energies of Azidoketene $\mathrm{O}=\mathrm{C}=\mathrm{CH}-\mathrm{NNN}$ and Isocyanatoketene $\mathrm{O}=\mathrm{C}=\mathrm{CH}-\mathrm{N}=\mathrm{C}=\mathrm{O}$. J Appl Computat Math 5: e142.

100. Heidari (2016) Study of Irradiations to Enhance the Induces the Dissociation of Hydrogen Bonds between Peptide Chains and Transition from Helix Structure to Random Coil Structure Using ATR-FTIR, Raman and 1HNMR Spectroscopies. $J$ Biomol Res Ther 5: e146.

101. Heidari (2016) Future Prospects of Point Fluorescence Spectroscopy, Fluorescence Imaging and Fluorescence Endoscopy in Photodynamic Therapy (PDT) for Cancer Cells. J Bioanal Biomed 8: e135.

102. Heidari (2016) A Bio-Spectroscopic Study of DNA Density and Color Role as Determining Factor for Absorbed Irradiation in Cancer Cells. Adv Cancer Prev 1: e102.

103. Heidari (2016) Manufacturing Process of Solar Cells Using Cadmium Oxide (CdO) and Rhodium (III) Oxide (Rh2O3) Nanoparticles. J Biotechnol Biomater 6: e125.

104. Heidari (2016) A Novel Experimental and Computational Approach to Photobiosimulation of Telomeric DNA/RNA: A Biospectroscopic and Photobiological Study. J Res Development 4: 144.

105. Heidari (2016) Biochemical and Pharmacodynamical Study of Microporous Molecularly Imprinted Polymer Selective for Vancomycin, Teicoplanin, Oritavancin, Telavancin and Dalbavancin Binding. Biochem Physiol 5: e146.

106. Heidari (2016) Anti-Cancer Effect of UV Irradiation at Presence of Cadmium Oxide (CdO) Nanoparticles on DNA of Cancer Cells: A Photodynamic Therapy Study. Arch Cancer Res 4: 1

107. Heidari (2016) Biospectroscopic Study on Multi-Component Reactions (MCRs) in Two A-Type and B-Type Conformations of Nucleic Acids to Determine Ligand Binding Modes, Binding Constant and Stability of Nucleic Acids in Cadmium Oxide (CdO) Nanoparticles-Nucleic Acids Complexes as Anti-Cancer Drugs. Arch Cancer Res 4: 2 .

108. Heidari (2016) Simulation of Temperature Distribution of DNA/RNA of Human Cancer Cells Using Time-Dependent Bio-Heat Equation and Nd: YAG Lasers. Arch Cancer Res.4: 2

109. Heidari (2016) Quantitative Structure-Activity Relationship (QSAR) Approximation for Cadmium Oxide (CdO) and Rhodium (III) Oxide (Rh2O3) Nanoparticles as AntiCancer Drugs for the Catalytic Formation of Proviral DNA from Viral RNA Using Multiple Linear and Non-Linear Correlation Approach. Ann Clin Lab Res 4: 1.

110. Heidari (2016) Biomedical Study of Cancer Cells DNA Therapy Using Laser Irradiations at Presence of Intelligent Nanoparticles. J Biomedical Sci 5: 2. 
Heidari A (2020) Stochastic study of relativistic lutetium nanoparticles moving in a quantum field of synchrotron radiation emission when charged lutetium nanoparticles are accelerated radially in human cancer cells, tissues and tumors treatment

111. Heidari (2016) Measurement the Amount of Vitamin D2 (Ergocalciferol), Vitamin D3 (Cholecalciferol) and Absorbable Calcium (Ca2+), Iron (II) (Fe2+), Magnesium $(\mathrm{Mg} 2+)$, Phosphate (PO4-) and Zinc ( $\mathrm{Zn} 2+)$ in Apricot Using High-Performance Liquid Chromatography (HPLC) and Spectroscopic Techniques $J$ Biom Biostat 7: 292.

112. Heidari (2016) Spectroscopy and Quantum Mechanics of the Helium Dimer (He2+), Neon Dimer $(\mathrm{Ne} 2+)$, Argon Dimer (Ar2+), Krypton Dimer $(\mathrm{Kr} 2+)$, Xenon Dimer $(\mathrm{Xe} 2+)$, Radon Dimer(Rn2+) and Ununoctium Dimer (Uuo2+) Molecular Cations. Chem Sci J 7: e112.

113. Heidari (2016) Human Toxicity Photodynamic Therapy Studies on DNA/RNA Complexes as a Promising New Sensitizer for the Treatment of Malignant Tumors Using Bio-Spectroscopic Techniques. Journal Drug Metab Toxicol 7: e129.

114. Heidari (2016) Novel and Stable Modifications of Intelligent Cadmium Oxide (CdO) Nanoparticles as Anti-Cancer Drug in Formation of Nucleic Acids Complexes for Human Cancer Cells' Treatment. Biochem Pharmacol 5: 207.

115. Heidari (2016) A Combined Computational and QM/MM Molecular Dynamics Study on Boron Nitride Nanotubes (BNNTs), Amorphous Boron Nitride Nanotubes (a-BNNTs) and Hexagonal Boron Nitride Nanotubes (h-BNNTs) as Hydrogen Storage. Struct Chem Crystallogr Commun 2: 1.

116. Heidari (2016) Pharmaceutical and Analytical Chemistry Study of Cadmium Oxide (CdO) Nanoparticles Synthesis Methods and Properties as Anti-Cancer Drug and its Effect on Human Cancer Cells. Pharm Anal Chem Open Access 2: 113.

117. Heidari (2016) A Chemotherapeutic and Biospectroscopic Investigation of the Interaction of Double-Standard DNA/RNA-Binding Molecules with Cadmium Oxide (CdO) and Rhodium (III) Oxide (Rh2O3) Nanoparticles as Anti-Cancer Drugs for Cancer Cells' Treatment. Chemo Open Access 5: e129.

118. Heidari (2016) Pharmacokinetics and Experimental Therapeutic Study of DNA and Other Biomolecules Using Lasers: Advantages and Applications. J Pharmacokinet Exp Ther 1: e005.

119. Heidari (2016) Determination of Ratio and Stability Constant of DNA/RNA in Human Cancer Cells and Cadmium Oxide (CdO) Nanoparticles Complexes Using Analytical Electrochemical and Spectroscopic Techniques. Insights Anal Electrochem 2: 1.

120. Heidari (2016) Discriminate between Antibacterial and Non-Antibacterial Drugs Artificial Neutral Networks of a Multilayer Perceptron (MLP) Type Using a Set of Topological Descriptors. Journal Heavy Met Toxicity Dis 1: 2.

121. Heidari (2016) Combined Theoretical and Computational Study of the BelousovZhabotinsky Chaotic Reaction and Curtius Rearrangement for Synthesis of Mechlorethamine, Cisplatin, Streptozotocin, Cyclophosphamide, Melphalan, Busulphan and BCNU as Anti-Cancer Drugs. Insights Med Phys 1: 2.

122. Heidari (2016) A Translational Biomedical Approach to Structural Arrangement of Amino Acids' Complexes: A Combined Theoretical and Computational Study. Transl Biomed 7: 2.

123. Heidari (2016) Ab Initio and Density Functional Theory (DFT) Studies of Dynamic NMR Shielding Tensors and Vibrational Frequencies of DNA/RNA and Cadmium Oxide (CdO) Nanoparticles Complexes in Human Cancer Cells. Journal Nanomedine Biotherapeutic Discov 6: e144.

124. Heidari (2016) Molecular Dynamics and Monte-Carlo Simulations for Replacement Sugars in Insulin Resistance, Obesity, LDL Cholesterol, Triglycerides, Metabolic Syndrome, Type 2 Diabetes and Cardiovascular Disease: A Glycobiological Study. Journal Glycobiol 5: e111.

125. Heidari (2016) Synthesis and Study of 5-[(Phenylsulfonyl)Amino]-1,3,4Thiadiazole-2-Sulfonamide as Potential Anti-Pertussis Drug Using Chromatography and Spectroscopy Techniques. Transl Med 6: e138.

126. Heidari (2016) Nitrogen, Oxygen, Phosphorus and Sulphur Heterocyclic Anti-Cancer Nano Drugs Separation in the Supercritical Fluid of Ozone (O3) Using SoaveRedlich-Kwong (SRK) and Pang-Robinson (PR) Equations. Electronic Journal Biol 12: 4 .

127. Heidari (2016) An Analytical and Computational Infrared Spectroscopic Review of Vibrational Modes in Nucleic Acids. Austin J Anal Pharm Chem 3: 1058.

128. Heidari (2016) Phase, Composition and Morphology Study and Analysis of Os-Pd/ HfC Nanocomposites. Nano Res Appl 2: 1 .

129. Heidari (2016) Vibrational Spectroscopic Study of Intensities and Shifts of Symmetric Vibration Modes of Ozone Diluted by Cumene. International Journal of Advanced Chemistry 4: 5-9.
130. Heidari (2016) Study of the Role of Anti-Cancer Molecules with Different Sizes for Decreasing Corresponding Bulk Tumor Multiple Organs or Tissues. Arch Can Res 4: 2 .

131. Heidari (2016) Genomics and Proteomics Studies of Zolpidem, Necopidem, Alpidem, Saripidem, Miroprofen, Zolimidine, Olprinone and Abafungin as AntiTumor, Peptide Antibiotics, Antiviral and Central Nervous System (CNS) Drugs Journal Data Mining Genomics \& Proteomics 7: e125.

132. Heidari (2016) Pharmacogenomics and Pharmacoproteomics Studies of Phosphodiesterase-5 (PDE5) Inhibitors and Paclitaxel Albumin-Stabilized Nanoparticles as Sandwiched Anti-Cancer Nano Drugs between Two DNA/RNA Molecules of Human Cancer Cells Journal Pharmacogenomics Pharmacoproteomics 7: e153.

133. Heidari (2016) Biotranslational Medical and Biospectroscopic Studies of Cadmium Oxide (CdO) Nanoparticles-DNA/RNA Straight and Cycle Chain Complexes as Potent Anti-Viral, Anti-Tumor and Anti-Microbial Drugs: A Clinical Approach. Transl Biomed 7: 2.

134. Heidari (2016) A Comparative Study on Simultaneous Determination and Separation of Adsorbed Cadmium Oxide (CdO) Nanoparticles on DNA/RNA of Human Cancer Cells Using Biospectroscopic Techniques and Dielectrophoresis (DEP) Method Arch Can Res 4: 2.

135. Heidari (2016) Cheminformatics and System Chemistry of Cisplatin, Carboplatin, Nedaplatin, Oxaliplatin, Heptaplatin and Lobaplatin as Anti-Cancer Nano Drugs: A Combined Computational and Experimental Study. Journal Inform Data Min 1: 3.

136. Heidari (2016) Linear and Non-Linear Quantitative Structure-Anti-Cancer-Activity Relationship (QSACAR) Study of Hydrous Ruthenium (IV) Oxide (RuO2) Nanoparticles as Non-Nucleoside Reverse Transcriptase Inhibitors (NNRTIs) and Anti-Cancer Nano Drugs. Journal Integr Oncol 5: e110.

137. Heidari (2016) Synthesis, Characterization and Biospectroscopic Studies of Cadmium Oxide (CdO) Nanoparticles-Nucleic Acids Complexes Absence of Soluble Polymer as a Protective Agent Using Nucleic Acids Condensation and Solution Reduction Method. Journal Nanosci Curr Res 1: e101.

138. Heidari (2016) Coplanarity and Collinearity of 4'-Dinonyl-2,2'-Bithiazole in One Domain of Bleomycin and Pingyangmycin to be Responsible for Binding of Cadmium Oxide $(\mathrm{CdO})$ Nanoparticles to DNA/RNA Bidentate Ligands as AntiTumor Nano Drug. Int J Drug Dev \& Res 8: 007-008.

139. Heidari (2016) A Pharmacovigilance Study on Linear and Non-Linear Quantitative Structure (Chromatographic) Retention Relationships (QSRR) Models for the Prediction of Retention Time of Anti-Cancer Nano Drugs under Synchrotron Radiations. Journal Pharmacovigil 4: e161.

140. Heidari (2016) Nanotechnology in Preparation of Semipermeable Polymers. Journal Adv Chem Eng 6: 157.

141. Heidari (2016) A Gastrointestinal Study on Linear and Non-Linear Quantitative Structure (Chromatographic) Retention Relationships (QSRR) Models for Analysis 5-Aminosalicylates Nano Particles as Digestive System Nano Drugs under Synchrotron Radiations. Journal Gastrointest Dig Syst 6: e119.

142. Heidari (2016) DNA/RNA Fragmentation and Cytolysis in Human Cancer Cells Treated with Diphthamide Nano Particles Derivatives. Biomedical Data Mining 5: e102.

143. Heidari (2016) A Successful Strategy for the Prediction of Solubility in the Construction of Quantitative Structure-Activity Relationship (QSAR) and Quantitative Structure-Property Relationship (QSPR) under Synchrotron Radiations Using Genetic Function Approximation (GFA) Algorithm. J Mol Biol Biotechnol 1: 1.

144. Heidari (2016) Computational Study on Molecular Structures of C20, C60, C240, C540, C960, C2160 and C3840 Fullerene Nano Molecules under Synchrotron Radiations Using Fuzzy Logic. J Material Sci Eng 5: 282.

145. Heidari (2016) Graph Theoretical Analysis of Zigzag Polyhexamethylene Biguanide, Polyhexamethylene Adipamide, Polyhexamethylene Biguanide Gauze and Polyhexamethylene Biguanide Hydrochloride (PHMB) Boron Nitride Nanotubes (BNNTs), Amorphous Boron Nitride Nanotubes (a-BNNTs) and Hexagonal Boron Nitride Nanotubes (h-BNNTs). Journal Appl Computat Math 5: e143.

146. Heidari (2016) The Impact of High Resolution Imaging on Diagnosis. Int J Clin Med Imaging 3: 1000e101.

147. Heidari (2016) A Comparative Study of Conformational Behavior of Isotretinoin (13Cis Retinoic Acid) and Tretinoin (All-Trans Retinoic Acid (ATRA)) Nano Particles as Anti-Cancer Nano Drugs under Synchrotron Radiations Using Hartree-Fock (HF) and Density Functional Theory (DFT) Methods. Insights in Biomed 1: 2. 
Heidari A (2020) Stochastic study of relativistic lutetium nanoparticles moving in a quantum field of synchrotron radiation emission when charged lutetium nanoparticles are accelerated radially in human cancer cells, tissues and tumors treatment

148. Heidari (2016) Advances in Logic, Operations and Computational Mathematics. Journal Appl Computat Math 5: 5.

149. Heidari (2016) Mathematical Equations in Predicting Physical Behavior. J Appl Computat Math 5: 5 .

150. Heidari (2016) Chemotherapy a Last Resort for Cancer Treatment. Chemo Open Access 5: 4.

151. Heidari (2016) Separation and Pre-Concentration of Metal Cations-DNA/RNA Chelates Using Molecular Beam Mass Spectrometry with Tunable Vacuum Ultraviolet (VUV) Synchrotron Radiation and Various Analytical Methods. Mass Spectrom Purif Tech 2: e101

152. Heidari (2016) Yoctosecond Quantitative Structure-Activity Relationship (QSAR) and Quantitative Structure-Property Relationship (QSPR) under Synchrotron Radiations Studies for Prediction of Solubility of Anti-Cancer Nano Drugs in Aqueous Solutions Using Genetic Function Approximation (GFA) Algorithm. Insight Pharm Res 1: 1.

153. Heidari (2016) Cancer Risk Prediction and Assessment in Human Cells under Synchrotron Radiations Using Quantitative Structure Activity Relationship (QSAR) and Quantitative Structure Properties Relationship (QSPR) Studies. Int J Clin Med Imaging 3: 516.

154. Heidari (2016) A Novel Approach to Biology. Electronic J Biol 12: 4.

155. Heidari (2016) Innovative Biomedical Equipment's for Diagnosis and Treatment. Journal Bioengineer \& Biomedical Sci 6: 2.

156. Heidari (2016) Integrating Precision Cancer Medicine into Healthcare, Medicare Reimbursement Changes and the Practice of Oncology: Trends in Oncology Medicine and Practices. Journal Oncol Med \& Pract 1: 2.

157. Heidari (2016) Promoting Convergence in Biomedical and Biomaterials Sciences and Silk Proteins for Biomedical and Biomaterials Applications: An Introduction to Materials in Medicine and Bioengineering Perspectives. Journal Bioengineer \& Biomedical Sci 6: 3.

158. Heidari (2017) X-Ray Fluorescence and X-Ray Diffraction Analysis on Discrete Element Modeling of Nano Powder Metallurgy Processes in Optimal Container Design. Journal Powder Metall Min 6: 1.

159. Heidari (2017) Biomolecular Spectroscopy and Dynamics of Nano-Sized Molecules and Clusters as Cross-Linking-Induced Anti-Cancer and Immune-Oncology Nano Drugs Delivery in DNA/RNA of Human Cancer Cells' Membranes under Synchrotron Radiations: A Payload-Based Perspective. Arch Chem Res 1: 2.

160. Heidari (2017) Deficiencies in Repair of Double-Standard DNA/RNA-Binding Molecules Identified in Many Types of Solid and Liquid Tumors Oncology in Human Body for Advancing Cancer Immunotherapy Using Computer Simulations and Data Analysis: Number of Mutations in a Synchronous Tumor Varies by Age and Type of Synchronous Cancer. J Appl Bioinforma Comput Biol 6: 1.

161. Heidari (2017) Electronic Coupling among the Five Nanomolecules Shuts Down Quantum Tunneling in the Presence and Absence of an Applied Magnetic Field for Indication of the Dimer or other Provide Different Influences on the Magnetic Behavior of Single Molecular Magnets (SMMs) as Qubits for Quantum Computing. Glob J Res Rev 4: 2.

162. Heidari (2017) Polymorphism in Nano-Sized Graphene Ligand-Induced Transformation of Au38-xAgx/xCux(SPh-tBu)24 to Au36-xAgx/xCux(SPh-tBu)24 $(\mathrm{x}=1-12)$ Nanomolecules for Synthesis of Au144-xAgx/xCux[(SR)60, (SC4)60, (SC6)60, (SC12)60, (PET)60, (p-MBA)60, (F)60, (Cl)60, (Br)60, (I)60, (At)60, (Uus) 60 and (SC6H13)60] Nano Clusters as Anti-Cancer Nano Drugs. J Nanomater Mol Nanotechnol 6: 3.

163. Heidari (2017) Biomedical Resource Oncology and Data Mining to Enable Resource Discovery in Medical, Medicinal, Clinical, Pharmaceutical, Chemical and Translational Research and Their Applications in Cancer Research. Int J Biomed Data Min 6: e103.

164. Heidari (2017) Study of Synthesis, Pharmacokinetics, Pharmacodynamics, Dosing, Stability, Safety and Efficacy of Olympiadane Nanomolecules as Agent for Cancer Enzymotherapy, Immunotherapy, Chemotherapy, Radiotherapy, Hormone Therapy and Targeted Therapy under Synchrotorn Radiation. J Dev Drugs 6: e154.

165. Heidari (2017) A Novel Approach to Future Horizon of Top Seven Biomedical Research Topics to Watch in 2017: Alzheimer's, Ebola, Hypersomnia, Human Immunodeficiency Virus (HIV), Tuberculosis (TB), Microbiome/Antibiotic Resistance and Endovascular Stroke. J Bioengineer \& Biomedical Sci 7: e127.

166. Heidari (2017) Opinion on Computational Fluid Dynamics (CFD) Technique. Fluid Mech Open Acc 4: 157.
167. Heidari (2017) Concurrent Diagnosis of Oncology Influence Outcomes in Emergency General Surgery for Colorectal Cancer and Multiple Sclerosis (MS) Treatment Using Magnetic Resonance Imaging (MRI) and Au329(SR)84, Au329-xAgx(SR)84 Au144(SR)60, Au68(SR)36, Au30(SR)18, Au102(SPh)44, Au38(SPh)24, Au38(SC2H4Ph)24, Au21S(SAdm)15, Au36(pMBA)24 and Au25(pMBA)18 Nano Clusters. J Surgery Emerg Med 1: 21

168. Heidari (2017) Developmental Cell Biology in Adult Stem Cells Death and Autophagy to Trigger a Preventive Allergic Reaction to Common Airborne Allergens under Synchrotron Radiation Using Nanotechnology for Therapeutic Goals in Particular Allergy Shots (Immunotherapy). Cell Biol 6: 1.

169. Heidari (2017) Changing Metal Powder Characteristics for Elimination of the Heavy Metals Toxicity and Diseases in Disruption of Extracellular Matrix (ECM) Protein Adjustment in Cancer Metastases Induced by Osteosarcoma, Chondrosarcoma, Carcinoid, Carcinoma, Ewing's Sarcoma, Fibrosarcoma and Secondary Hematopoietic Solid or Soft Tissue Tumors. Journal Powder Metall Min 6: 170

170. Heidari (2017) Nanomedicine-Based Combination Anti-Cancer Therapy between Nucleic Acids and Anti-Cancer Nano Drugs in Covalent Nano Drugs Delivery Systems for Selective Imaging and Treatment of Human Brain Tumors Using Hyaluronic Acid, Alguronic Acid and Sodium Hyaluronate as Anti-Cancer Nano Drugs and Nucleic Acids Delivery under Synchrotron Radiation. Am J Drug Deliv $5: 2$

171. Heidari (2017) Clinical Trials of Dendritic Cell Therapies for Cancer Exposing Vulnerabilities in Human Cancer Cells' Metabolism and Metabolomics: New Discoveries, Unique Features Inform New Therapeutic Opportunities, Biotech's Bumpy Road to the Market and Elucidating the Biochemical Programs that Support Cancer Initiation and Progression. J Biol Med Science 1: e103.

172. Heidari (2017) The Design Graphene-Based Nanosheets as a New Nanomaterial in Anti-Cancer Therapy and Delivery of Chemotherapeutics and Biological Nano Drugs for Liposomal Anti-Cancer Nano Drugs and Gene Delivery. Br Biomed Bull 5: 305.

173. Heidari (2017) Integrative Approach to Biological Networks for Emerging Roles of Proteomics, Genomics and Transcriptomics in the Discovery and Validation of Human Colorectal Cancer Biomarkers from DNA/RNA Sequencing Data under Synchrotron Radiation. Transcriptomics 5: e117.

174. Heidari (2017) Elimination of the Heavy Metals Toxicity and Diseases in Disruption of Extracellular Matrix (ECM) Proteins and Cell Adhesion Intelligent Nanomolecules Adjustment in Cancer Metastases Using Metalloenzymes and under Synchrotron Radiation. Lett Health Biol Sci 2: 1-4.

175. Heidari (2017) Treatment of Breast Cancer Brain Metastases through a Targeted Nanomolecule Drug Delivery System Based on Dopamine Functionalized MultiWall Carbon Nanotubes (MWCNTs) Coated with Nano Graphene Oxide (GO) and Protonated Polyaniline (PANI) in Situ During the Polymerization of Aniline Autogenic Nanoparticles for the Delivery of Anti-Cancer Nano Drugs under Synchrotron Radiation. Br J Res 4: 16.

176. Heidari (2017) Sedative, Analgesic and Ultrasound-Mediated Gastrointestinal Nano Drugs Delivery for Gastrointestinal Endoscopic Procedure, Nano Drug-Induced Gastrointestinal Disorders and Nano Drug Treatment of Gastric Acidity. Res Rep Gastroenterol 1: 1.

177. Heidari (2017) Synthesis, Pharmacokinetics, Pharmacodynamics, Dosing, Stability, Safety and Efficacy of Orphan Nano Drugs to Treat High Cholesterol and Related Conditions and to Prevent Cardiovascular Disease under Synchrotron Radiation. Journal Pharm Sci Emerg Drugs 5: 1.

178. Heidari (2017) Non-Linear Compact Proton Synchrotrons to Improve Human Cancer Cells and Tissues Treatments and Diagnostics through Particle Therapy Accelerators with Monochromatic Microbeams. Journal Cell Biol Mol Sci 2: 1-5.

179. Heidari (2017) Design of Targeted Metal Chelation Therapeutics Nanocapsules as Colloidal Carriers and Blood-Brain Barrier (BBB) Translocation to Targeted Deliver Anti-Cancer Nano Drugs into the Human Brain to Treat Alzheimer's Disease under Synchrotron Radiation. Journal Nanotechnol Material Sci 4: 1-5.

180. Gobato R, Heidari A (2017) Calculations Using Quantum Chemistry for Inorganic Molecule Simulation BeLi2SeSi. Science Journal of Analytical Chemistry 5: 76-85.

181. Heidari (2017) Different High-Resolution Simulations of Medical, Medicinal, Clinical, Pharmaceutical and Therapeutics Oncology of Human Lung Cancer Translational Anti-Cancer Nano Drugs Delivery Treatment Process under Synchrotron and X-Ray Radiations. Journal Med Oncol 1: 1.

182. Heidari (2017) A Modern Ethnomedicinal Technique for Transformation, Prevention and Treatment of Human Malignant Gliomas Tumors into Human Benign Gliomas Tumors under Synchrotron Radiation. Am J Ethnomed 4: 10. 
Heidari A (2020) Stochastic study of relativistic lutetium nanoparticles moving in a quantum field of synchrotron radiation emission when charged lutetium nanoparticles are accelerated radially in human cancer cells, tissues and tumors treatment

183. Heidari (2017) Active Targeted Nanoparticles for Anti-Cancer Nano Drugs Delivery across the Blood-Brain Barrier for Human Brain Cancer Treatment, Multiple Sclerosis (MS) and Alzheimer's Diseases Using Chemical Modifications of AntiCancer Nano Drugs or Drug-Nanoparticles through Zika Virus (ZIKV) Nanocarriers under Synchrotron Radiation. Journal Med Chem Toxicol 2: 1-5.

184. Heidari (2017) Investigation of Medical, Medicinal, Clinical and Pharmaceutical Applications of Estradiol, Mestranol (Norlutin), Norethindrone (NET), Norethisterone Acetate (NETA), Norethisterone Enanthate (NETE) and Testosterone Nanoparticles as Biological Imaging, Cell Labeling, Anti-Microbial Agents and Anti-Cancer Nano Drugs in Nanomedicines Based Drug Delivery Systems for Anti-Cancer Targeting and Treatment. Parana Journal of Science and Education 3: 4.

185. Heidari (2017) A Comparative Computational and Experimental Study on Different Vibrational Biospectroscopy Methods, Techniques and Applications for Human Cancer Cells in Tumor Tissues Simulation, Modeling, Research, Diagnosis and Treatment. Open J Anal Bioanal Chem 1: 014-020.

186. Heidari (2017) Combination of DNA/RNA Ligands and Linear/Non-Linear VisibleSynchrotron Radiation-Driven N-Doped Ordered Mesoporous Cadmium Oxide (CdO) Nanoparticles Photocatalysts Channels Resulted in an Interesting Synergistic Effect Enhancing Catalytic Anti-Cancer Activity. Enz Eng 6: 1.

187. Heidari (2017) Modern Approaches in Designing Ferritin, Ferritin Light Chain, Transferrin, Beta-2 Transferrin and Bacterioferritin-Based Anti-Cancer Nano Drugs Encapsulating Nanosphere as DNA-Binding Proteins from Starved Cells (DPS). Mod Appro Drug Des 1.

188. Heidari (2017) Potency of Human Interferon $\beta$-1a and Human Interferon $\beta-1 b$ in Enzymotherapy, Immunotherapy, Chemotherapy, Radiotherapy, Hormone Therapy and Targeted Therapy of Encephalomyelitis Disseminate/Multiple Sclerosis (MS) and Hepatitis A, B, C, D, E, F and G Virus Enter and Targets Liver Cells. Journal Proteomics Enzymol 6: 1.

189. Heidari (2017) Transport Therapeutic Active Targeting of Human Brain Tumors Enable Anti-Cancer Nanodrugs Delivery across the Blood-Brain Barrier (BBB) to Treat Brain Diseases Using Nanoparticles and Nanocarriers under Synchrotron Radiation. Journal Pharm Pharmaceutics 4: 1-5.

190. Heidari (2017) Combinatorial Therapeutic Approaches to DNA/RNA and Benzylpenicillin (Penicillin G), Fluoxetine Hydrochloride (Prozac and Sarafem), Propofol (Diprivan), Acetylsalicylic Acid (ASA) (Aspirin), Naproxen Sodium (Aleve and Naprosyn) and Dextromethamphetamine Nanocapsules with Surface Conjugated DNA/RNA to Targeted Nano Drugs for Enhanced Anti-Cancer Efficacy and Targeted Cancer Therapy Using Nano Drugs Delivery Systems. Ann Adv Chem 1: 061-069.

191. Heidari (2017) High-Resolution Simulations of Human Brain Cancer Translational Nano Drugs Delivery Treatment Process under Synchrotron Radiation. Journal Transl Res 1: 1-3.

192. Heidari (2017) Investigation of Anti-Cancer Nano Drugs' Effects' Trend on Human Pancreas Cancer Cells and Tissues Prevention, Diagnosis and Treatment Process under Synchrotron and X-Ray Radiations with the Passage of Time Using Mathematica. Current Trends Anal Bioanal Chem 1: 36-41.

193. Heidari (2017) Pros and Cons Controversy on Molecular Imaging and Dynamics of Double-Standard DNA/RNA of Human Preserving Stem Cells-Binding Nano Molecules with Androgens/Anabolic Steroids (AAS) or Testosterone Derivatives through Tracking of Helium-4 Nucleus (Alpha Particle) Using Synchrotron Radiation. Arch Biotechnol Biomed 1: 067-0100.

194. Heidari (2017) Visualizing Metabolic Changes in Probing Human Cancer Cells and Tissues Metabolism Using Vivo 1H or Proton NMR, 13C NMR, 15N NMR and 31P NMR Spectroscopy and Self-Organizing Maps under Synchrotron Radiation. SOJ Mater Sci Eng 5: 1-6.

195. Heidari (2017) Cavity Ring-Down Spectroscopy (CRDS), Circular Dichroism Spectroscopy, Cold Vapour Atomic Fluorescence Spectroscopy and Correlation Spectroscopy Comparative Study on Malignant and Benign Human Cancer Cells and Tissues with the Passage of Time under Synchrotron Radiation. Enliven Challenges Cancer Detect Ther 4: e001.

196. Heidari (2017) Laser Spectroscopy, Laser-Induced Breakdown Spectroscopy and Laser-Induced Plasma Spectroscopy Comparative Study on Malignant and Benign Human Cancer Cells and Tissues with the Passage of Time under Synchrotron Radiation. Int J Hepatol Gastroenterol 3: 079-084.

197. Heidari (2017) Time-Resolved Spectroscopy and Time-Stretch Spectroscopy Comparative Study on Malignant and Benign Human Cancer Cells and Tissues with the Passage of Time under Synchrotron Radiation. Enliven: Pharmacovigilance and Drug Safety 4: e001.
198. Heidari (2017) Overview of the Role of Vitamins in Reducing Negative Effect of Decapeptyl (Triptorelin Acetate or Pamoate Salts) on Prostate Cancer Cells and Tissues in Prostate Cancer Treatment Process through Transformation of Malignant Prostate Tumors into Benign Prostate Tumors under Synchrotron Radiation. Open J Anal Bioanal Chem 1: 021-026.

199. Heidari (2017) Electron Phenomenological Spectroscopy, Electron Paramagnetic Resonance (EPR) Spectroscopy and Electron Spin Resonance (ESR) Spectroscopy Comparative Study on Malignant and Benign Human Cancer Cells and Tissues with the Passage of Time under Synchrotron Radiation. Austin J Anal Pharm Chem 4: 1091.

200. Heidari (2017) Therapeutic Nanomedicine Different High-Resolution Experimental Images and Computational Simulations for Human Brain Cancer Cells and Tissues Using Nanocarriers Deliver DNA/RNA to Brain Tumors under Synchrotron Radiation with the Passage of Time Using Mathematica and MATLAB. Madridge $J$ Nano Tech Science 2: 77-83.

201. Heidari (2017) A Consensus and Prospective Study on Restoring Cadmium Oxide (CdO) Nanoparticles Sensitivity in Recurrent Ovarian Cancer by Extending the Cadmium Oxide (CdO) Nanoparticles-Free Interval Using Synchrotron Radiation Therapy as Antibody-Drug Conjugate for the Treatment of Limited-Stage Small Cell Diverse Epithelial Cancers. Cancer Clin Res Rep 1: 2.

202. Heidari (2017) A Novel and Modern Experimental Imaging and Spectroscopy Comparative Study on Malignant and Benign Human Cancer Cells and Tissues with the Passage of Time under White Synchrotron Radiation. Cancer Sci Res Open Access 4: 1-8.

203. Heidari (2017) Different High-Resolution Simulations of Medical, Medicinal, Clinical, Pharmaceutical and Therapeutics Oncology of Human Breast Cancer Translational Nano Drugs Delivery Treatment Process under Synchrotron and X-Ray Radiations. J Oral Cancer Res 1: 12-17.

204. Heidari (2017) Vibrational Decihertz (dHz), Centihertz (cHz), Millihertz (mHz) Microhertz $(\mu \mathrm{Hz})$, Nanohertz (nHz), Picohertz (pHz), Femtohertz (fHz), Attohertz $(\mathrm{aHz})$, Zeptohertz $(\mathrm{zHz})$ and Yoctohertz $(\mathrm{yHz})$ Imaging and Spectroscopy Comparative Study on Malignant and Benign Human Cancer Cells and Tissues under Synchrotron Radiation. International Journal of Biomedicine 7: 335-340.

205. Heidari (2017) Force Spectroscopy and Fluorescence Spectroscopy Comparative Study on Malignant and Benign Human Cancer Cells and Tissues with the Passage of Time under Synchrotron Radiation. EC Cancer 2: 239-246.

206. Heidari (2017) Photoacoustic Spectroscopy, Photoemission Spectroscopy and Photothermal Spectroscopy Comparative Study on Malignant and Benign Human Cancer Cells and Tissues with the Passage of Time under Synchrotron Radiation. BAOJ Cancer Res Ther 3: 045-052.

207. Heidari (2017) J-Spectroscopy, Exchange Spectroscopy (EXSY), Nucle $\neg$ a Overhauser Effect Spectroscopy (NOESY) and Total Correlation Spectroscopy (TOCSY) Comparative Study on Malignant and Benign Human Cancer Cells and Tissues under Synchrotron Radiation. EMS Eng Sci J 1: 006-013.

208. Heidari (2017) Neutron Spin Echo Spectroscopy and Spin Noise Spectroscopy Comparative Study on Malignant and Benign Human Cancer Cells and Tissues with the Passage of Time under Synchrotron Radiation. Int J Biopharm Sci 1: 103-107.

209. Heidari (2017) Vibrational Decahertz (daHz), Hectohertz (hHz), Kilohertz (kHz), Megahertz (MHz), Gigahertz (GHz), Terahertz (THz), Petahertz (PHz), Exahertz $(\mathrm{EHz})$, Zettahertz $(\mathrm{ZHz})$ and Yottahertz $(\mathrm{YHz})$ Imaging and Spectroscopy Comparative Study on Malignant and Benign Human Cancer Cells and Tissues under Synchrotron Radiation. Madridge J Anal Sci Instrum 2: 41-46.

210. Heidari (2018) Two-Dimensional Infrared Correlation Spectroscopy, Linear TwoDimensional Infrared Spectroscopy and Non-Linear Two-Dimensional Infrared Spectroscopy Comparative Study on Malignant and Benign Human Cancer Cells and Tissues under Synchrotron Radiation with the Passage of Time. J Mater Sci Nanotechnol 6: 101.

211. Heidari (2018) Fourier Transform Infrared (FTIR) Spectroscopy, Near-Infrared Spectroscopy (NIRS) and Mid-Infrared Spectroscopy (MIRS) Comparative Study on Malignant and Benign Human Cancer Cells and Tissues under Synchrotron Radiation with the Passage of Time. Int J Nanotechnol Nanomed 3: 1-6.

212. Heidari (2018) Infrared Photo Dissociation Spectroscopy and Infrared Correlation Table Spectroscopy Comparative Study on Malignant and Benign Human Cancer Cells and Tissues under Synchrotron Radiation with the Passage of Time. Austin Pharmacol Pharm 3: 1011.

213. Heidari (2017) Novel and Transcendental Prevention, Diagnosis and Treatment Strategies for Investigation of Interaction among Human Blood Cancer Cells, Tissues, Tumors and Metastases with Synchrotron Radiation under Anti-Cancer Nano Drugs Delivery Efficacy Using MATLAB Modeling and Simulation. Madridge J Nov Drug Res 1: 18-24. 
Heidari A (2020) Stochastic study of relativistic lutetium nanoparticles moving in a quantum field of synchrotron radiation emission when charged lutetium nanoparticles are accelerated radially in human cancer cells, tissues and tumors treatment

214. Heidari (2018) Comparative Study on Malignant and Benign Human Cancer Cells and Tissues with the Passage of Time under Synchrotron Radiation. Open Access $J$ Trans Med Res 2: 00026-00032.

215. Heidari A (2018) Planting of Jaboticaba Trees for Landscape Repair of Degraded Area. Landscape Architecture and Regional Planning 3: 1-9.

216. Heidari (2018) Fluorescence Spectroscopy, Phosphorescence Spectroscopy and Luminescence Spectroscopy Comparative Study on Malignant and Benign Human Cancer Cells and Tissues under Synchrotron Radiation with the Passage of Time. SM J Clin Med Imaging 4: 1018

217. Heidari (2018) Nuclear Inelastic Scattering Spectroscopy (NISS) and Nuclear Inelastic Absorption Spectroscopy (NIAS) Comparative Study on Malignant and Benign Human Cancer Cells and Tissues under Synchrotron Radiation. Int J Pharm Sci $2: 1-14$

218. Heidari (2018) X-Ray Diffraction (XRD), Powder X-Ray Diffraction (PXRD) and Energy-Dispersive X-Ray Diffraction (EDXRD) Comparative Study on Malignan and Benign Human Cancer Cells and Tissues under Synchrotron Radiation. J Oncol Res 2: 1-14.

219. Heidari (2018) Correlation Two-Dimensional Nuclear Magnetic Reso $\neg$ nance (NMR) (2D-NMR) (COSY) Imaging and Spectrosco $\neg$ py Comparative Study on Malignan and Benign Human Cancer Cells and Tissues under Synchrotron Radiation. EMS Can Sci 1: 1 .

220. Heidari (2018) Thermal Spectroscopy, Photothermal Spectroscopy, Thermal Microspectroscopy, Photothermal Microspectroscopy, Thermal Macrospectroscopy and Photothermal Macrospectroscopy Comparative Study on Malignant and Benign Human Cancer Cells and Tissues with the Passage of Time under Synchrotron Radiation. SM J Biometrics Biostat 3: 1024.

221. Heidari (2018) A Modern and Comprehensive Experimental Biospectroscopic Comparative Study on Human Common Cancers' Cells, Tissues and Tumors before and after Synchrotron Radiation Therapy. Open Acc J Oncol Med 1

222. Heidari (2018) Heteronuclear Correlation Experiments such as Heteronuclear SingleQuantum Correlation Spectroscopy (HSQC), Heteronuclear Multiple-Quantum Correlation Spectroscopy (HMQC) and Heteronuclear Multiple-Bond Correlation Spectroscopy (HMBC) Comparative Study on Malignant and Benign Human Endocrinology and Thyroid Cancer Cells and Tissues under Synchrotron Radiation. J Endocrinol Thyroid Res 3: 555603.

223. Heidari (2018) Nuclear Resonance Vibrational Spectroscopy (NRVS), Nuclear Inelastic Scattering Spectroscopy (NISS), Nuclear Inelastic Absorption Spectroscopy (NIAS) and Nuclear Resonant Inelastic X-Ray Scattering Spectroscopy (NRIXSS) Comparative Study on Malignant and Benign Human Cancer Cells and Tissues under Synchrotron Radiation. Int J Bioorg Chem Mol Biol 6: 1-5.

224. Heidari (2018) A Novel and Modern Experimental Approach to Vibrational Circular Dichroism Spectroscopy and Video Spectroscopy Comparative Study on Malignant and Benign Human Cancer Cells and Tissues with the Passage of Time under White and Monochromatic Synchrotron Radiation. Glob J Endocrinol Metab 1: 000514 000519.

225. Heidari (2018) Pros and Cons Controversy on Heteronuclear Correlation Experiments such as Heteronuclear Single-Quantum Correlation Spectroscopy (HSQC), Heteronuclear Multiple-Quantum Correlation Spectroscopy (HMQC) and Heteronuclear Multiple-Bond Correlation Spectroscopy (HMBC) Comparative Study on Malignant and Benign Human Cancer Cells and Tissues under Synchrotron Radiation. EMS Pharma J 1: 002-008.

226. Heidari (2018) A Modern Comparative and Comprehensive Experimental Biospectroscopic Study on Different Types of Infrared Spectroscopy of Malignan and Benign Human Cancer Cells and Tissues with the Passage of Time under Synchrotron Radiation. J Analyt Molecul Tech 3: 8

227. Heidari (2018) Investigation of Cancer Types Using Synchrotron Technology for Proton Beam Therapy: An Experimental Biospectroscopic Comparative Study. European Modern Studies Journal 2: 13-29.

228. Heidari (2018) Saturated Spectroscopy and Unsaturated Spectroscopy Comparative Study on Malignant and Benign Human Cancer Cells and Tissues with the Passage of Time under Synchrotron Radiation. Imaging J Clin Medical Sci 5: 001-007.

229. Heidari (2018) Small-Angle Neutron Scattering (SANS) and Wide-Angle X-Ray Diffraction (WAXD) Comparative Study on Malignant and Benign Human Cancer Cells and Tissues under Synchrotron Radiation. Int J Bioorg Chem Mol Biol 6: 1-6.

230. Heidari (2018) Investigation of Bladder Cancer, Breast Cancer, Colorectal Cancer, Endometrial Cancer, Kidney Cancer, Leukemia, Liver, Lung Cancer, Melanoma, Non-Hodgkin Lymphoma, Pancreatic Cancer, Prostate Cancer, Thyroid Cancer and Non-Melanoma Skin Cancer Using Synchrotron Technology for Proton Beam Therapy: An Experimental Biospectroscopic Comparative Study. Ther Res Skin Dis

231. Heidari (2018) Attenuated Total Reflectance Fourier Transform Infrared (ATRFTIR) Spectroscopy, Micro-Attenuated Total Reflectance Fourier Transform Infrared (Micro-ATR-FTIR) Spectroscopy and Macro-Attenuated Total Reflectance Fourie Transform Infrared (Macro-ATR-FTIR) Spectroscopy Comparative Study on Malignant and Benign Human Cancer Cells and Tissues under Synchrotron Radiation with the Passage of Time. International Journal of Chemistry Papers 2: 1-12.

232. Heidari (2018) Mössbauer Spectroscopy, Mössbauer Emission Spectroscopy and 57Fe Mössbauer Spectroscopy Comparative Study on Malignant and Benign Human Cancer Cells and Tissues under Synchrotron Radiation. Acta Scientific Cancer Biology 23: 17-20.

233. Heidari (2018) Comparative Study on Malignant and Benign Human Cancer Cells and Tissues under Synchrotron Radiation with the Passage of Time. Organic \& Medicinal Chem 6: 555676

234. Heidari (2018) Correlation Spectroscopy, Exclusive Correlation Spectroscopy and Total Correlation Spectroscopy Comparative Study on Malignant and Benign Human AIDS-Related Cancers Cells and Tissues with the Passage of Time under Synchrotron Radiation. Int J Bioanal Biomed 2: 001-007.

235. Heidari (2018) Biomedical Instrumentation and Applications of Biospectroscopic Methods and Techniques in Malignant and Benign Human Cancer Cells and Tissues Studies under Synchrotron Radiation and Anti-Cancer Nano Drugs Delivery. Am J Nanotechnol Nanomed 1: 001-009.

236. Heidari (2018) Vivo 1H or Proton NMR, 13C NMR, 15N NMR and 31P NMR spectroscopy comparative study on malignant and benign human cancer cells and tissues under synchrotron radiation. Ann Biomet Biostat 1: 1001.

237. Heidari (2018) Grazing-Incidence Small-Angle Neutron Scattering (GISANS) and Grazing-Incidence X-Ray Diffraction (GIXD) Comparative Study on Malignant and Benign Human Cancer Cells, Tissues and Tumors under Synchrotron Radiation. Ann Cardiovasc Surg 1: 1006

238. Heidari (2018) Adsorption Isotherms and Kinetics of Multi-Walled Carbon Nanotubes (MWCNTs), Boron Nitride Nanotubes (BNNTs), Amorphous Boron Nitride Nanotubes (a-BNNTs) and Hexagonal Boron Nitride Nanotubes (h-BNNTs) for Eliminating Carcinoma, Sarcoma, Lymphoma, Leukemia, Germ Cell Tumor and Blastoma Cancer Cells and Tissues. Clin Med Rev Case Rep 5: 201.

239. Heidari (2018) Correlation Spectroscopy (COSY), Exclusive Correlation Spectroscopy (ECOSY), Total Correlation Spectroscopy (TOCSY), Incredible Natural-Abundance Double-Quantum Transfer Experiment (INADEQUATE), Heteronuclear Single-Quantum Correlation Spectroscopy (HSQC), Heteronuclear Multiple-Bond Correlation Spectroscopy (HMBC), Nuclear Overhauser Effect Spectroscopy (NOESY) and Rotating Frame Nuclear Overhauser Effect Spectroscopy (ROESY) Comparative Study on Malignant and Benign Human Cancer Cells and Tissues under Synchrotron Radiation. Acta Scientific Pharmaceutical Sciences 25: 30-35.

240. Heidari (2018) Small-Angle X-Ray Scattering (SAXS), Ultra-Small Angle X-Ray Scattering (USAXS), Fluctuation X-Ray Scattering (FXS), Wide-Angle X-Ray Scattering (WAXS), Grazing-Incidence Small-Angle X-Ray Scattering (GISAXS), Grazing-Incidence Wide-Angle X-Ray Scattering (GIWAXS), Small-Angle Neutron Scattering (SANS), Grazing-Incidence Small-Angle Neutron Scattering (GISANS), X-Ray Diffraction (XRD), Powder X-Ray Diffraction (PXRD), Wide-Angle X-Ray Diffraction (WAXD), Grazing-Incidence X-Ray Diffraction (GIXD) and EnergyDispersive X-Ray Diffraction (EDXRD) Comparative Study on Malignant and Benign Human Cancer Cells and Tissues under Synchrotron Radiation. Oncol Res Rev 1: 1-10.

241. Heidari (2018) Pump-Probe Spectroscopy and Transient Grating Spectroscopy Comparative Study on Malignant and Benign Human Cancer Cells and Tissues with the Passage of Time under Synchrotron Radiation. Adv Material Sci Engg 2: 1-7.

242. Heidari (2018) Grazing-Incidence Small-Angle X-Ray Scattering (GISAXS) and Grazing-Incidence Wide-Angle X-Ray Scattering (GIWAXS) Comparative Study on Malignant and Benign Human Cancer Cells and Tissues under Synchrotron Radiation. Insights Pharmacol Pharm Sci 1: 1-8.

243. Heidari (2018) Acoustic Spectroscopy, Acoustic Resonance Spectroscopy and Auge Spectroscopy Comparative Study on Anti-Cancer Nano Drugs Delivery in Malignan and Benign Human Cancer Cells and Tissues with the Passage of Time under Synchrotron Radiation. Nanosci Technol 5: 1-9.

244. Heidari (2018) Niobium, Technetium, Ruthenium, Rhodium, Hafnium, Rhenium, Osmium and Iridium Ions Incorporation into the Nano Polymeric Matrix (NPM) 
Heidari A (2020) Stochastic study of relativistic lutetium nanoparticles moving in a quantum field of synchrotron radiation emission when charged lutetium nanoparticles are accelerated radially in human cancer cells, tissues and tumors treatment

by Immersion of the Nano Polymeric Modified Electrode (NPME) as Molecular Enzymes and Drug Targets for Human Cancer Cells, Tissues and Tumors Treatment under Synchrotron and Synchrocyclotron Radiations. Nanomed Nanotechnol 3: 000138.

245. Heidari (2018) Homonuclear Correlation Experiments such as Homonuclear SingleQuantum Correlation Spectroscopy (HSQC), Homonuclear Multiple-Quantum Correlation Spectroscopy (HMQC) and Homonuclear Multiple-Bond Correlation Spectroscopy (HMBC) Comparative Study on Malignant and Benign Human Cancer Cells and Tissues under Synchrotron Radiation. Austin J Proteomics Bioinform \& Genomics 5: 1024.

246. Heidari (2018) Atomic Force Microscopy Based Infrared (AFM-IR) Spectroscopy and Nuclear Resonance Vibrational Spectroscopy Comparative Study on Malignan and Benign Human Cancer Cells and Tissues under Synchrotron Radiation with the Passage of Time. J Appl Biotechnol Bioeng 5: 142-148.

247. Heidari (2018) Time-Dependent Vibrational Spectral Analysis of Malignant and Benign Human Cancer Cells and Tissues under Synchrotron Radiation. J Cancer Oncol 2: 000124.

248. Heidari (2018) Palauamine and Olympiadane Nano Molecules Incorporation into the Nano Polymeric Matrix (NPM) by Immersion of the Nano Polymeric Modified Electrode (NPME) as Molecular Enzymes and Drug Targets for Human Cancer Cells, Tissues and Tumors Treatment under Synchrotron and Synchrocyclotron Radiations. Arc Org Inorg Chem Sci 3.

249. Gobato R, Heidari A (2018) Infrared Spectrum and Sites of Action of Sanguinarine by Molecular Mechanics and ab initio Methods. International Journal of Atmospheric and Oceanic Sciences 2: 1-9.

250. Heidari (2018) Angelic Acid, Diabolic Acids, Draculin and Miraculin Nano Molecules Incorporation into the Nano Polymeric Matrix (NPM) by Immersion of the Nano Polymeric Modified Electrode (NPME) as Molecular Enzymes and Drug Targets for Human Cancer Cells, Tissues and Tumors Treatment Under Synchrotron and Synchrocyclotron Radiations. Med \& Analy Chem Int J 2: 000111.

251. Heidari (2018) Gamma Linolenic Methyl Ester, 5-Heptadeca-5,8,11-Trienyl 1,3,4-Oxadiazole-2-Thiol, Sulphoquinovosyl Diacyl Glycerol, Ruscogenin, Nocturnoside B, Protodioscine B, Parquisoside-B, Leiocarposide, Narangenin, 7-Methoxy Hespertin, Lupeol, Rosemariquinone, Rosmanol and Rosemadiol Nano Molecules Incorporation into the Nano Polymeric Matrix (NPM) by Immersion of the Nano Polymeric Modified Electrode (NPME) as Molecular Enzymes and Drug Targets for Human Cancer Cells, Tissues and Tumors Treatment under Synchrotron and Synchrocyclotron Radiations. Int J Pharma Anal Acta 2: 007-014.

252. Heidari (2018) Fourier Transform Infrared (FTIR) Spectroscopy, Attenuated Total Reflectance Fourier Transform Infrared (ATR-FTIR) Spectroscopy, Micro-Attenuated Total Reflectance Fourier Transform Infrared (Micro-ATR-FTIR) Spectroscopy, Macro-Attenuated Total Reflectance Fourier Transform Infrared (Macro-ATRFTIR) Spectroscopy, Two-Dimensional Infrared Correlation Spectroscopy, Linear Two-Dimensional Infrared Spectroscopy, Non-Linear Two-Dimensional Infrared Spectroscopy, Atomic Force Microscopy Based Infrared (AFM-IR) Spectroscopy, Infrared Photodissociation Spectroscopy, Infrared Correlation Table Spectroscopy, Near-Infrared Spectroscopy (NIRS), Mid-Infrared Spectroscopy (MIRS), Nuclear Resonance Vibrational Spectroscopy, Thermal Infrared Spectroscopy and Photothermal Infrared Spectroscopy Comparative Study on Malignant and Benign Human Cancer Cells and Tissues under Synchrotron Radiation with the Passage of Time. Glob Imaging Insights 3: 1-14.

253. Heidari (2018) Heteronuclear Single-Quantum Correlation Spectroscopy (HSQC) and Heteronuclear Multiple-Bond Correlation Spectroscopy (HMBC) Comparative Study on Malignant and Benign Human Cancer Cells, Tissues and Tumors under Synchrotron and Synchrocyclotron Radiations. Chronicle of Medicine and Surgery 23: 144-156.

254. Heidari (2018) Tetrakis [3, 5-bis (Trifluoromethyl) Phenyl] Borate (BARF)-Enhanced Precatalyst Preparation Stabilization and Initiation (EPPSI) Nano Molecules. Medical Research and Clinical Case Reports 2: 113-126.

255. Heidari (2018) Sydnone, Münchnone, Montréalone, Mogone, Montelukast, Quebecol and Palau'amine-Enhanced Precatalyst Preparation Stabilization and Initiation (EPPSI) Nano Molecules. Sur Cas Stud Op Acc 2: 1.

256. Heidari (2018) Fornacite, Orotic Acid, Rhamnetin, Sodium Ethyl Xanthate (SEX) and Spermine (Spermidine or Polyamine) Nanomolecules Incorporation into the Nanopolymeric Matrix (NPM). International Journal of Biochemistry and Biomolecules 4: 1-19.

257. Heidari (2018) Putrescine, Cadaverine, Spermine and Spermidine-Enhanced Precatalyst Preparation Stabilization and Initiation (EPPSI) Nano Molecules. Parana Journal of Science and Education 4: 1-14.
258. Heidari (2018) Cadaverine (1,5-Pentanediamine or Pentamethylenediamine), Diethyl Azodicarboxylate (DEAD or DEADCAT) and Putrescine (Tetramethylenediamine) Nano Molecules Incorporation into the Nano Polymeric Matrix (NPM) by Immersion of the Nano Polymeric Modified Electrode (NPME) as Molecular Enzymes and Drug Targets for Human Cancer Cells, Tissues and Tumors Treatment under Synchrotron and Synchrocyclotron Radiations. Hiv and Sexual Health Open Access Open Journal 1: 4-11.

259. Heidari (2018) Improving the Performance of Nano-Endofullerenes in Polyaniline Nanostructure-Based Biosensors by Covering Californium Colloidal Nanoparticles with Multi-Walled Carbon Nanotubes. Journal of Advances in Nanomaterials 3 : $1-28$.

260. Gobato R, Heidari A (2018) Molecular Mechanics and Quantum Chemical Study on Sites of Action of Sanguinarine Using Vibrational Spectroscopy Based on Molecular Mechanics and Quantum Chemical Calculations. Malaysian Journal of Chemistry 20: $1-23$.

261. Heidari (2018) Vibrational Biospectroscopic Studies on Anti-cancer Nanopharmaceuticals (Part I). Malaysian Journal of Chemistry 20: 33-73.

262. Heidari (2018) Vibrational Biospectroscopic Studies on Anti-cancer Nanopharmaceuticals (Part II). Malaysian Journal of Chemistry 20: 74-117.

263. Heidari (2018) Uranocene (U(C8H8)2) and Bis(Cyclooctatetraene)Iron (Fe(C8H8)2 or $\mathrm{Fe}(\mathrm{COT}) 2)$-Enhanced Precatalyst Preparation Stabilization and Initiation (EPPSI) Nano Molecules. Chemistry Reports 1: 1-16.

264. Heidari (2018) Biomedical Systematic and Emerging Technological Study on Human Malignant and Benign Cancer Cells and Tissues Biospectroscopic Analysis under Synchrotron Radiation. Glob Imaging Insights 3: 1-7.

265. Heidari (2018) Deep-Level Transient Spectroscopy and X-Ray Photoelectron Spectroscopy (XPS) Comparative Study on Malignant and Benign Human Cance Cells and Tissues with the Passage of Time under Synchrotron Radiation. Res Dev Material Sci 7.

266. Heidari (2018) C70-Carboxyfullerenes Nano Molecules Incorporation into the Nano Polymeric Matrix (NPM) by Immersion of the Nano Polymeric Modified Electrode (NPME) as Molecular Enzymes and Drug Targets for Human Cancer Cells, Tissues and Tumors Treatment under Synchrotron and Synchrocyclotron Radiations. Glob Imaging Insights 3: 1-7.

267. Heidari (2018) The Effect of Temperature on Cadmium Oxide (CdO) Nanoparticles Produced by Synchrotron Radiation in the Human Cancer Cells, Tissues and Tumors. International Journal of Advanced Chemistry 6: 140-156.

268. Heidari (2018) A Clinical and Molecular Pathology Investigation of Correlation Spectroscopy (COSY), Exclusive Correlation Spectroscopy (ECOSY), Total Correlation Spectroscopy (TOCSY), Heteronuclear Single-Quantum Correlation Spectroscopy (HSQC) and Heteronuclear Multiple-Bond Correlation Spectroscopy (HMBC) Comparative Study on Malignant and Benign Human Cancer Cells, Tissues and Tumors under Synchrotron and Synchrocyclotron Radiations Using Cyclotron versus Synchrotron, Synchrocyclotron and the Large Hadron Collider (LHC) for Delivery of Proton and Helium Ion (Charged Particle) Beams for Oncology Radiotherapy. European Journal of Advances in Engineering and Technology 5: 414426 .

269. Heidari (2018) Nano Molecules Incorporation into the Nano Polymeric Matrix (NPM) by Immersion of the Nano Polymeric Modified Electrode (NPME) as Molecular Enzymes and Drug Targets for Human Cancer Cells, Tissues and Tumor Treatment under Synchrotron and Synchrocyclotron Radiations. J Oncol Res 1: 1-20.

270. Heidari (2018) Use of Molecular Enzymes in the Treatment of Chronic Disorders Canc Oncol Open Access J 1: 12-15.

271. Heidari (2018) Vibrational Biospectroscopic Study and Chemical Structure Analysis of Unsaturated Polyamides Nanoparticles as Anti-Cancer Polymeric Nanomedicines Using Synchrotron Radiation. International Journal of Advanced Chemistry 6: 167 189.

272. Heidari (2018) Adamantane, Irene, Naftazone and Pyridine-Enhanced Precatalyst Preparation Stabilization and Initiation (PEPPSI) Nano Molecules. Madridge J Nov Drug Res 2: 61-67.

273. Heidari (2018) Heteronuclear Single-Quantum Correlation Spectroscopy (HSQC) and Heteronuclear Multiple-Bond Correlation Spectroscopy (HMBC) Comparative Study on Malignant and Benign Human Cancer Cells and Tissues with the Passage of Time under Synchrotron Radiation. Madridge J Nov Drug Res 2: 68-74.

274. Heidari, Gobato R (2018) A Novel Approach to Reduce Toxicities and to Improve Bioavailabilities of DNA/RNA of Human Cancer Cells-Containing Cocaine (Coke), Lysergide (Lysergic Acid Diethyl Amide or LSD), $\Delta^{9}$-Tetrahydrocannabinol (THC) 
Heidari A (2020) Stochastic study of relativistic lutetium nanoparticles moving in a quantum field of synchrotron radiation emission when charged lutetium nanoparticles are accelerated radially in human cancer cells, tissues and tumors treatment

[(-)-trans- $\Delta^{9}$-Tetrahydrocannabinol], Theobromine (Xantheose), Caffeine, Aspartame (APM) (NutraSweet) and Zidovudine (ZDV) [Azidothymidine (AZT)] as AntiCancer Nano Drugs by Coassembly of Dual Anti-Cancer Nano Drugs to Inhibit DNA/RNA of Human Cancer Cells Drug Resistance. Parana Journal of Science and Education 4: 1-17.

275. Heidari (2018) Ultraviolet Photoelectron Spectroscopy (UPS) and Ultraviolet-Visible (UV-Vis) spectroscopy comparative study on malignant and benign human cancer cells and tissues with the passage of time under synchrotron radiation. Parana Journal of Science and Education 4: 18-33.

276. Gobato R, Heidari A (2018) The Creation of C13H20BeLi2SeSi. The Proposal of a Bio-Inorganic Molecule, Using Ab Initio Methods for the Genesis of a Nano Membrane. Arc Org Inorg Chem Sci 3.

277. Gobato R, Heidari A (2018) Using the quantum chemistry for genesis of a nano biomembrane with a combination of the elements $\mathrm{Be}, \mathrm{Li}, \mathrm{Se}, \mathrm{Si}, \mathrm{C}$ and $\mathrm{H}$. ResearchGate, see discussions, stats, and author profiles for this publication at: https://www.researchgate.net/publication/326201181

278. Gobato R, Heidari A (2018) Using the Quantum Chemistry for Genesis of a Nano Biomembrane with a Combination of the Elements Be, Li, Se, Si, C and H. $J$ Nanomed Res 7: 241-252.

279. Heidari (2018) Bastadins and Bastaranes-Enhanced Precatalyst Preparation Stabilization and Initiation (EPPSI) Nano Molecules. Glob Imaging Insights 3: 1-7.

280. Heidari (2018) Fucitol, Pterodactyladiene, DEAD or DEADCAT (DiEthy AzoDiCArboxylaTe), Skatole, the NanoPutians, Thebacon, Pikachurin, Tie Fighter, Spermidine and Mirasorvone Nano Molecules Incorporation into the Nano Polymeric Matrix (NPM) by Immersion of the Nano Polymeric Modified Electrode (NPME) as Molecular Enzymes and Drug Targets for Human Cancer Cells, Tissues and Tumors Treatment under Synchrotron and Synchrocyclotron Radiations. Glob Imaging Insights 3: 1-8.

281. Dadvar E, Heidari A (2018) A Review on Separation Techniques of Graphene Oxide (GO)/Base on Hybrid Polymer Membranes for Eradication of Dyes and Oil Compounds: Recent Progress in Graphene Oxide (GO)/Base on Polymer Membranes-Related Nanotechnologies. Clin Med Rev Case Rep 5: 228.

282. Heidari (2018) Gobato R (2018) First-Time Simulation of Deoxyuridine Monophosphate (dUMP) (Deoxyuridylic Acid or Deoxyuridylate) and Vomitoxin

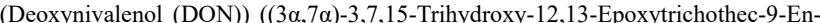
8-One)-Enhanced Precatalyst Preparation Stabilization and Initiation (EPPSI) Nano Molecules Incorporation into the Nano Polymeric Matrix (NPM) by Immersion of the Nano Polymeric Modified Electrode (NPME) as Molecular Enzymes and Drug Targets for Human Cancer Cells, Tissues and Tumors Treatment under Synchrotron and Synchrocyclotron Radiations. Parana Journal of Science and Education 4: 4667.

283. Heidari (2018) Buckminsterfullerene (Fullerene), Bullvalene, Dickite and Josiphos Ligands Nano Molecules Incorporation into the Nano Polymeric Matrix (NPM) by Immersion of the Nano Polymeric Modified Electrode (NPME) as Molecular Enzymes and Drug Targets for Human Hematology and Thromboembolic Diseases Prevention, Diagnosis and Treatment under Synchrotron and Synchrocyclotron Radiations. Glob Imaging Insights 3: 1-7.

284. Heidari (2018) Fluctuation X-Ray Scattering (FXS) and Wide-Angle X-Ray Scattering (WAXS) Comparative Study on Malignant and Benign Human Cancer Cells and Tissues under Synchrotron Radiation. Glob Imaging Insights 3: 1-7.

285. Heidari (2018) A Novel Approach to Correlation Spectroscopy (COSY), Exclusive Correlation Spectroscopy (ECOSY), Total Correlation Spectroscopy (TOCSY), Incredible Natural-Abundance Double-Quantum Transfer Experiment (INADEQUATE), Heteronuclear Single-Quantum Correlation Spectroscopy (HSQC), Heteronuclear Multiple-Bond Correlation Spectroscopy (HMBC), Nuclear Overhauser Effect Spectroscopy (NOESY) and Rotating Frame Nuclear Overhauser Effect Spectroscopy (ROESY) Comparative Study on Malignant and Benign Human Cancer Cells and Tissues under Synchrotron Radiation. Glob Imaging Insights 3: 1-9.

286. Heidari (2018) Terphenyl-Based Reversible Receptor with Rhodamine, RhodamineBased Molecular Probe, Rhodamine-Based Using the Spirolactam Ring Opening, Rhodamine B with Ferrocene Substituent, Calix[4]Arene-Based Receptor, Thioether + Aniline-Derived Ligand Framework Linked to a Fluorescein Platform, Mercuryfluor-1 (Flourescent Probe), N,N'-Dibenzyl-1,4,10,13-Tetraraoxa-7,16Diazacyclooctadecane and Terphenyl-Based Reversible Receptor with Pyrene and Quinoline as the Fluorophores-Enhanced Precatalyst Preparation Stabilization and Initiation (EPPSI) Nano Molecules. Glob Imaging Insights 3: 1-9.

287. Heidari (2018) Small-Angle X-Ray Scattering (SAXS), Ultra-Small Angle X-Ray Scattering (USAXS), Fluctuation X-Ray Scattering (FXS), Wide-Angle X-Ray Scattering (WAXS), Grazing-Incidence Small-Angle X-Ray Scattering (GISAXS)
Grazing-Incidence Wide-Angle X-Ray Scattering (GIWAXS), Small-Angle Neutron Scattering (SANS), Grazing-Incidence Small-Angle Neutron Scattering (GISANS), X-Ray Diffraction (XRD), Powder X-Ray Diffraction (PXRD), Wide-Angle X-Ray Diffraction (WAXD), Grazing-Incidence X-Ray Diffraction (GIXD) and EnergyDispersive X-Ray Diffraction (EDXRD) Comparative Study on Malignant and Benign Human Cancer Cells and Tissues under Synchrotron Radiation. Glob Imaging Insights 3: 1-10.

288. Heidari (2018) Nuclear Resonant Inelastic X-Ray Scattering Spectroscopy (NRIXSS) and Nuclear Resonance Vibrational Spectroscopy (NRVS) Comparative Study on Malignant and Benign Human Cancer Cells and Tissues under Synchrotron Radiation. Glob Imaging Insights 3: 1-7.

289. Heidari (2018) Small-Angle X-Ray Scattering (SAXS) and Ultra-Small Angle X-Ray Scattering (USAXS) Comparative Study on Malignant and Benign Human Cancer Cells and Tissues under Synchrotron Radiation. Glob Imaging Insights 3: 1-7.

290. Heidari (2018) Curious Chloride ( $\mathrm{CmCl} 3)$ and Titanic Chloride (TiCl4)-Enhanced Precatalyst Preparation Stabilization and Initiation (EPPSI) nano molecules for cancer treatment and cellular therapeutics. $J$ Cancer Research and Therapeutic Interventions 1: 01-10.

291. Gobato R, Heidari A, Mitra A (2018) Spectroscopy and Dipole Moment of the Molecule C13H20BeLi2SeSi via Quantum Chemistry Using Ab Initio, Hartree-Fock Method in the Base Set CC-pVTZ and 6-311G**(3df, 3pd). Arc Org Inorg Chem Sci 3: 402-409.

292. Heidari (2018) C60 and C70-Encapsulating Carbon Nanotubes Incorporation into the Nano Polymeric Matrix (NPM) by Immersion of the Nano Polymeric Modified Electrode (NPME) as Molecular Enzymes and Drug Targets for Human Cancer Cells, Tissues and Tumors Treatment under Synchrotron and Synchrocyclotron Radiations. Integr Mol Med 5: 1-8.

293. Heidari (2018) Two-Dimensional (2D) 1H or Proton NMR, 13C NMR, 15N NMR and 31P NMR Spectroscopy Comparative Study on Malignant and Benign Human Cancer Cells and Tissues under Synchrotron Radiation with the Passage of Time. Glob Imaging Insights 3: 1-8.

294. Heidari (2018) FT-Raman Spectroscopy, Coherent Anti-Stokes Raman Spectroscopy (CARS) and Raman Optical Activity Spectroscopy (ROAS) Comparative Study on Malignant and Benign Human Cancer Cells and Tissues with the Passage of Time under Synchrotron Radiation. Glob Imaging Insights 3: 1-8.

295. Heidari (2018) A Modern and Comprehensive Investigation of Inelastic Electron Tunneling Spectroscopy (IETS) and Scanning Tunneling Spectroscopy on Malignan and Benign Human Cancer Cells, Tissues and Tumors through Optimizing Synchrotron Microbeam Radiotherapy for Human Cancer Treatments and Diagnostics: An Experimental Biospectroscopic Comparative Study. Glob Imaging Insights 3: 1-8.

296. Heidari (2018) A Hypertension Approach to Thermal Infrared Spectroscopy and Photothermal Infrared Spectroscopy Comparative Study on Malignant and Benign Human Cancer Cells and Tissues under Synchrotron Radiation with the Passage of Time. Glob Imaging Insights 3: 1-8.

297. Heidari (2018) Incredible Natural-Abundance Double-Quantum Transfer Experimen (INADEQUATE), Nuclear Overhauser Effect Spectroscopy (NOESY) and Rotating Frame Nuclear Overhauser Effect Spectroscopy (ROESY) Comparative Study on Malignant and Benign Human Cancer Cells and Tissues under Synchrotron Radiation. Glob Imaging Insights 3: 1-8.

298. Heidari (2018) 2-Amino-9-((1S, 3R, 4R)-4-Hydroxy-3-(Hydroxymethyl)-2 Methylenecyclopentyl)-1H-Purin-6(9H)-One, 2-Amino-9-((1R, 3R, 4R)-4-Hydroxy3-(Hydroxymethyl)-2-Methylenecyclopentyl)-1H-Purin-6(9H)-One, 2-Amino9-((1R, 3R, 4S)-4-Hydroxy-3-(Hydroxymethyl)-2-Methylenecyclopentyl)-1HPurin-6(9H)-One and 2-Amino-9-((1S, 3R, 4S)-4-Hydroxy-3-(Hydroxymethyl)2-Methylenecyclopentyl)-1H-Purin-6(9H)-One-Enhanced Precatalyst Preparation Stabilization and Initiation Nano Molecules. Glob Imaging Insights 3: 1-9.

299. Gobato R, Heidari A, Mitra A (2018) Spectroscopy and Dipole Moment of the Molecule C13H20BeLi2SeSi via Quantum Chemistry Using Ab Initio, Hartree-Fock Method in the Base Set CC-pVTZ and 6-311G**(3df, 3pd). American Journal of Quantum Chemistry and Molecular Spectroscopy 2: 9-17.

300. Heidari (2018) Production of Electrochemiluminescence (ECL) Biosensor Using Os$\mathrm{Pd} / \mathrm{HfC}$ Nanocomposites for Detecting and Tracking of Human Gastroenterological Cancer Cells, Tissues and Tumors. Int J Med Nano Res 5: 022-034.

301. Heidari (2018) Enhancing the Raman Scattering for Diagnosis and Treatment of Human Cancer Cells, Tissues and Tumors Using Cadmium Oxide (CdO) Nanoparticles. J Toxicol Risk Assess 4: 012-025. 
Heidari A (2020) Stochastic study of relativistic lutetium nanoparticles moving in a quantum field of synchrotron radiation emission when charged lutetium nanoparticles are accelerated radially in human cancer cells, tissues and tumors treatment

302. Heidari (2018) Human Malignant and Benign Human Cancer Cells and Tissues Biospectroscopic Analysis under Synchrotron Radiation Using Anti-Cancer Nano Drugs Delivery. Integr Mol Med 5: 1-13.

303. Heidari (2018) Analogous Nano Compounds of the Form M(C8H8)2 Exist for $\mathrm{M}=$ (Nd, Tb, Pu, Pa, Np, Th, and Yb)-Enhanced Precatalyst Preparation Stabilization and Initiation (EPPSI) Nano Molecules. Integr Mol Med 5: 1-8.

304. Heidari (2018) Hadron Spectroscopy, Baryon Spectroscopy and Meson Spectroscopy Comparative Study on Malignant and Benign Human Cancer Cells and Tissues under Synchrotron Radiation. Integr Mol Med 5: 1-8.

305. Gobato R, Gobato MRR, Heidari A (2019) Raman Spectroscopy Study of the Nano Molecule C13H20BeLi2SeSi Using ab initio and Hartree-Fock Methods in the Basis Set CC-pVTZ and 6-311G** (3df, 3pd). International Journal of Advanced Engineering and Science 7: 14-35.

306. Heidari, Gobato R (2019) Evaluating the Effect of Anti-Cancer Nano Drugs Dosage and Reduced Leukemia and Polycythemia Vera Levels on Trend of the Human Blood and Bone Marrow Cancers under Synchrotron Radiation. Trends in Res 2: 1-8.

307. Heidari, Gobato R (2019) Assessing the Variety of Synchrotron, Synchrocyclotron and LASER Radiations and Their Roles and Applications in Human Cancer Cells, Tissues and Tumors Diagnosis and Treatment. Trends in Res 2: 1-8.

308. Heidari, Gobato R (2019) Pros and Cons Controversy on Malignant Human Cancer Cells, Tissues and Tumors Transformation Process to Benign Human Cancer Cells, Tissues and Tumors. Trends in Res, 2: 1-8.

309. Heidari, Gobato R (2019) Three-Dimensional (3D) Simulations of Human Cancer Cells, Tissues and Tumors for Using in Human Cancer Cells, Tissues and Tumors Diagnosis and Treatment as a Powerful Tool in Human Cancer Cells, Tissues and Tumors Research and Anti-Cancer Nano Drugs Sensitivity and Delivery Area Discovery and Evaluation. Trends in Res 2: 1-8.

310. Heidari, Gobato R (2019) Investigation of Energy Production by Synchrotron, Synchrocyclotron and LASER Radiations in Human Cancer Cells, Tissues and Tumors and Evaluation of Their Effective on Human Cancer Cells, Tissues and Tumors Treatment Trend. Trends in Res 2: 1-8.

311. Heidari, Gobato R (2019) High-Resolution Mapping of DNA/RNA Hypermethylation and Hypomethylation Process in Human Cancer Cells, Tissues and Tumors under Synchrotron Radiation. Trends in Res 2: 1-9.

312. Heidari (2019) A Novel and Comprehensive Study on Manufacturing and Fabrication Nanoparticles Methods and Techniques for Processing Cadmium Oxide (CdO) Nanoparticles Colloidal Solution. Glob Imaging Insights 4: 1-8.

313. Heidari (2019) A Combined Experimental and Computational Study on the Catalytic Effect of Aluminum Nitride Nanocrystal (AIN) on the Polymerization of Benzene, Naphthalene, Anthracene, Phenanthrene, Chrysene and Tetracene. Glob Imaging Insights 4: 1-8.

314. Heidari (2019) Novel Experimental and Three-Dimensional (3D) Multiphysics Computational Framework of Michaelis-Menten Kinetics for Catalyst Processe Innovation, Characterization and Carrier Applications. Glob Imaging Insights 4: 1-8.

315. Heidari (2019) The Hydrolysis Constants of Copper (I) $(\mathrm{Cu}+)$ and Copper (II) (Cu2+) in Aqueous Solution as a Function of $\mathrm{pH}$ Using a Combination of $\mathrm{pH}$ Measurement and Biospectroscopic Methods and Techniques. Glob Imaging Insights 4: 1-8.

316. Heidari (2019) Vibrational Biospectroscopic Study of Ginormous Virus-Sized Macromolecule and Polypeptide Macromolecule as Mega Macromolecules Using Attenuated Total Reflectance-Fourier Transform Infrared (ATR-FTIR) Spectroscopy and Mathematica 11.3. Glob Imaging Insights 4: 1-8.

317. Heidari (2019) Three-Dimensional (3D) Imaging Spectroscopy of Carcinoma, Sarcoma, Leukemia, Lymphoma, Multiple Myeloma, Melanoma, Brain and Spinal Cord Tumors, Germ Cell Tumors, Neuroendocrine Tumors and Carcinoid Tumors under Synchrotron Radiation. Glob Imaging Insights 4: 1-9.

318. Gobato R, Heidari A (2019) Storm Vortex in the Center of Paraná State on June 6 2017: A Case Study. Sumerianz Journal of Scientific Research 2: 24-31.

319. Gobato R, Gobato MRR, Heidari A (2019) Attenuated Total Reflection-Fourier Transform Infrared (ATR-FTIR) Spectroscopy Study of the Nano Molecule C13H20BeLi2SeSi Using ab initio and Hartree-Fock Methods in the Basis Set RHF/ CC-pVTZ and RHF/6-311G** (3df, 3pd): An Experimental Challenge to Chemists. Chemistry Reports 2: 1-26.

320. Heidari (2019) Three-Dimensional (3D) Imaging Spectroscopy of Carcinoma, Sarcoma, Leukemia, Lymphoma, Multiple Myeloma, Melanoma, Brain and Spinal Cord Tumors, Germ Cell Tumors, Neuroendocrine Tumors and Carcinoid Tumors under Synchrocyclotron Radiation. Res Adv Biomed Sci Technol 1: 01-17.
321. Gobato R, Gobato MRR, Heidari A, Mitra A (2019) New Nano-Molecule KurumiC13H20BeLi2SeSi/C13H19BeLi2SeSi, and Raman Spectroscopy Using ab initio, Hartree-Fock Method in the Base Set CC-pVTZ and 6-311G** (3df, 3pd). $J$ Anal Pharm Res 8: 1-6.

322. Heidari, Esposito J, Caissutti A (2019) The Importance of Attenuated Total Reflectance Fourier Transform Infrared (ATR-FTIR) and Raman Bio $\neg$ spectroscopy of Single-Walled Carbon Nanotubes (SWCNT) and Multi-Walled Carbon Nanotubes (MWCNT) in Interpreting Infrared and Raman Spectra of Human Cancer Cells, Tissues and Tumors. Oncogen 2: 1-21.

323. Heidari (2019) Mechanism of Action and Their Side Effects at a Glance Prevention, Treatment and Management of Immune System and Human Cancer Nano Chemotherapy. Nanosci Technol 6: 1-4.

324. Heidari, Esposito J, Caissutti A (2019) The Quantum Entanglement Dynamics Induced by Non-Linear Interaction between a Moving Nano Molecule and a TwoMode Field with Two-Photon Transitions Using Reduced Von Neumann Entropy and Jaynes-Cummings Model for Human Cancer Cells, Tissues and Tumors Diagnosis. Int J Crit Care Emerg Med 5: 071-084.

325. Heidari, Esposito J, Caissutti A (2019) Palytoxin Time-Resolved Absorption and Resonance FT-IR and Raman Biospectroscopy and Density Functional Theory (DFT) Investigation of Vibronic-Mode Coupling Structure in Vibrational Spectra Analysis. $J$ Pharm Drug Res 3: 150-170.

326. Heidari, Esposito J, Caissutti A (2019) Aplysiatoxin Time-Resolved Absorption and Resonance FT-IR and Raman Biospectroscopy and Density Functional Theory (DFT) Investigation of Vibronic-Mode Coupling Structure in Vibrational Spectra Analysis. J Chem Sci Eng 2: 70-89.

327. Heidari, Esposito J, Caissutti A, Mitra A (2018) Spectroscopy and Dipole Moment of the Molecule C13H20BeLi2SeSi via Quantum Chemistry Using Ab initio, HartreeFock Method in the Base Set CC-pVTZ and 6-311G** (3df, 3pd). American Journal of Quantum Chemistry and Molecular Spectroscopy, 2: 9-17.

328. Heidari, Esposito J, Caissutti A (2019) Cyanotoxin Time-Resolved Absorption and Resonance FT-IR and Raman Biospectroscopy and Density Functional Theory (DFT) Investigation of Vibronic-Mode Coupling Structure in Vibrational Spectra Analysis. Br J Med Health Res 6: 21-60.

329. Heidari (2019) Potential and Theranostics Applications of Novel Anti-Cancer Nano Drugs Delivery Systems in Preparing for Clinical Trials of Synchrotron Microbeam Radiation Therapy (SMRT) and Synchrotron Stereotactic Radiotherapy (SSRT) for Treatment of Human Cancer Cells, Tissues and Tumors Using Image Guided Synchrotron Radiotherapy (IGSR). Ann Nanosci Nanotechnol 3: 1006-1019.

330. Heidari, Esposito J, Caissutti A (2019) Study of Anti-Cancer Properties of Thin Layers of Cadmium Oxide (CdO) Nanostructure. Int J Analyt Bioanalyt Methods 1: 003-022.

331. Heidari, Esposito J, Caissutti A (2019) Alpha-Conotoxin, Omega-Conotoxin and Mu-Conotoxin Time-Resolved Absorption and Resonance FT-IR and Raman Biospectroscopy and Density Functional Theory (DFT) Investigation of VibronicMode Coupling Structure in Vibrational Spectra Analysis. International Journal of Advanced Chemistry 7: 52-66.

332. Heidari (2019) Clinical and Medical Pros and Cons of Human Cancer Cells Enzymotherapy, Immunotherapy, Chemotherapy, Radiotherapy, Hormone Therapy and Targeted Therapy Process under Synchrotron Radiation: A Case Study on Mechanism of Action and Their Side Effects. Parana Journal of Science and Education 5: 1-23.

333. Heidari (2019) The Importance of the Power in CMOS Inverter Circuit of Synchrotron and Synchrocyclotron Radiations Using $50(\mathrm{~nm})$ and $100(\mathrm{~nm})$ Technologies and Reducing the Voltage of Power Supply. Radiother Oncol Int 1: 1002-1015.

334. Heidari, Esposito J, Caissutti A (2019) The Importance of Quantum Hydrodynamics (QHD) Approach to Single-Walled Carbon Nanotubes (SWCNT) and Multi-Walled Carbon Nanotubes (MWCNT) in Genetic Science. SCIOL Genet Sci 2: 113-129.

335. Heidari, Esposito J, Caissutti A (2019) Anatoxin-a and anatoxin-a(s) time-resolved absorption and resonance FT-IR and Raman Biospectroscopy and Density Functional Theory (DFT) Investigation of Vibronic-Mode Coupling Structure in Vibrational Spectra Analysis. Saudi J Biomed Res 4: 174-194.

336. Gobato R, Gobato MRR, Heidari A (2019) Evidence of Tornado Storm Hit the Counties of Rio Branco do Ivaí and Rosario de Ivaí, Southern Brazil. Sci Lett 7: $32-40$.

337. Jeyaraj M, Mahalingam V, Indhuleka A, Sennu P, Ho MS, Heidari A (2019) chemical analysis of surface water quality of river noyyal connected tank in Tirupur district, Tamil Nadu, India. Water and Energy International 62: 63-68. 
Heidari A (2020) Stochastic study of relativistic lutetium nanoparticles moving in a quantum field of synchrotron radiation emission when charged lutetium nanoparticles are accelerated radially in human cancer cells, tissues and tumors treatment

338. Heidari, Esposito J, Caissutti A (2019) 6-Methoxy-8-[[6-Methoxy-8-[[6-Methoxy2-Methyl-1-(2-Methylpropyl)-3,4- Dihydro-1H-Isoquinolin-7-yl]Oxy]-2-Methyl1-(2-Methylpropyl)-3,4-Dihydro-1H-Isoquinolin-7-yl]Oxy]-2-Methyl-1-(2 Methylpropyl)-3,4-Dihydro-1H-Isoquinolin-7-ol Time-Resolved Absorption and Resonance FT-IR and Raman Biospectroscopy and Density Functional Theory (DFT) Investigation of Vibronic-Mode Coupling Structure in Vibrational Spectra Analysis. J Adv Phys Chem 1: 1-6.

339. Heidari, Esposito J, Caissutti A (2019) Shiga Toxin and Shiga-Like Toxin (SLT) Time-Resolved Absorption and Resonance FT-IR and Raman Biospectroscopy and Density Functional Theory (DFT) Investigation of Vibronic-Mode Coupling Structure in Vibrational Spectra Analysis. Annal Biostat \& Biomed Appli 2: 1-4

340. Heidari, Esposito J, Caissutti A (2019) Alpha-Bungarotoxin, Beta-Bungarotoxin and Kappa-Bungarotoxin Time-Resolved Absorption and Resonance FT-IR and Raman Biospectroscopy and Density Functional Theory (DFT) Investigation of VibronicMode Coupling Structure in Vibrational Spectra Analysis. Archives of Pharmacology and Pharmaceutical Science ReDelve 1: 1-24.

341. Heidari, Esposito J, Caissutti A (2019) Okadaic Acid Time-Resolved Absorption and Resonance FT-IR and Raman Biospectroscopy and Density Functional Theory (DFT) Investigation of Vibronic-Mode Coupling Structure in Vibrational Spectra Analysis. Int J Analyt Bioanalyt Methods 1: 1-19.

342. Heidari (2019) Investigation of the Processes of Absorption, Distribution, Metabolism and Elimination (ADME) as Vital and Important Factors for Modulating Drug Action and Toxicity. Open Access J Oncol 2: 180010-180012.

343. Heidari, Esposito J, Caissutti A (2019) Pertussis Toxin Time-Resolved Absorption and Resonance FT-IR and Raman Biospectroscopy and Density Functional Theory (DFT) Investigation of Vibronic-Mode Coupling Structure in Vibrational Spectra Analysis. Chemistry Reports 1: 1-5.

344. Gobato R, Gobato MRR, Heidari A (2019) Rhodochrosite as Crystal Oscillator. Am J Biomed Sci \& Res 3: 187.

345. Heidari, Esposito J, Caissutti A(2019) Tetrodotoxin (TTX) Time-Resolved Absorption and Resonance FT-IR and Raman Biospectroscopy and Density Functional Theory (DFT) Investigation of Vibronic-Mode Coupling Structure in Vibrational Spectra Analysis. Journal of New Developments in Chemistry 2: 26-48.

346. Heidari, Esposito J, Caissutti A (2019) The Importance of Analysis of Vibronic-Mode Coupling Structure in Vibrational Spectra of Supramolecular Aggregates of $\left(\mathrm{CA}^{*} \mathrm{M}\right)$ Cyanuric Acid (CA) and Melamine (M) beyond the Franck-Condon Approximation. Journal of Clinical and Medical Images 2: 1-20.

347. Heidari, Esposito J, Caissutti A (2019) Microcystin-LR Time-Resolved Absorption and Resonance FT-IR and Raman Biospectroscopy and Density Functional Theory (DFT) Investigation of Vibronic-Mode Coupling Structure in Vibrational Spectra Analysis. Malaysian Journal of Chemistry 21: 70-95.

348. Heidari, Esposito J, Caissutti A (2019) Botulinum Toxin Time-Resolved Absorption and Resonance FT-IR and Raman Biospectroscopy and Density Functional Theory (DFT) Investigation of Vibronic-Mode Coupling Structure in Vibrational Spectra Analysis. Journal of Mechanical Design and Vibration 7: 1-15.

349. Heidari, Esposito J, Caissutti A (2019) Domoic Acid (DA) Time-Resolved Absorption and Resonance FT-IR and Raman Biospectroscopy and Density Functional Theory (DFT) Investigation of Vibronic-Mode Coupling Structure in Vibrational Spectra Analysis. Cientific Clinical Oncology Journal 2: 03-07.

350. Heidari, Esposito J, Caissutti A (2019) Surugatoxin (SGTX) Time-Resolved Absorption and Resonance FT-IR and Raman Biospectroscopy and Density Functional Theory (DFT) Investigation of Vibronic-Mode Coupling Structure in Vibrational Spectra Analysis. Cientific Clinical Oncology Journal 2: 14-18.

351. Heidari, Esposito J, Caissutti A (2019) Decarbamoylsaxitoxin Time-Resolved Absorption and Resonance FT-IR and Raman Biospectroscopy and Density Functional Theory (DFT) Investigation of Vibronic-Mode Coupling Structure in Vibrational Spectra Analysis. Cientific Clinical Oncology Journal 2: 19-23.

352. Heidari, Esposito J, Caissutti A (2019) Gonyautoxin (GTX) Time-Resolved Absorption and Resonance FT-IR and Raman Biospectroscopy and Density Functional Theory (DFT) Investigation of Vibronic-Mode Coupling Structure in Vibrational Spectra Analysis. Cientific Clinical Oncology Journal 2: 24-28.

353. Heidari, Esposito J, Caissutti A (2019) Hislrionicotoxin Time-Resolved Absorption and Resonance FT-IR and Raman Biospectroscopy and Density Functional Theory (DFT) Investigation of Vibronic-Mode Coupling Structure in Vibrational Spectra Analysis. Cientific Drug Delivery Research 1: 01-06.

354. Heidari, Esposito J, Caissutti A (2019) Dihydrokainic Acid Time-Resolved Absorption and Resonance FT-IR and Raman Biospectroscopy and Density Functional Theory
(DFT) Investigation of Vibronic-Mode Coupling Structure in Vibrational Spectra Analysis. Cientific Drug Delivery Research 1: 07-12.

355. Heidari, Esposito J, Caissutti A (2019) Aflatoxin B1 (AFB1), B2 (AFB2), G1 (AFG1), G2 (AFG2), M1 (AFM1), M2 (AFM2), Q1 (AFQ1) and P1 (AFP1) TimeResolved Absorption and Resonance FT-IR and Raman Biospectroscopy and Density Functional Theory (DFT) Investigation of Vibronic-Mode Coupling Structure in Vibrational Spectra Analysis. Cientific Drug Delivery Research 1: 25-32.

356. Heidari, Esposito J, Caissutti A (2019) Mycotoxin Time-Resolved Absorption and Resonance FT-IR and Raman Biospectroscopy and Density Functional Theory (DFT) Investigation of Vibronic-Mode Coupling Structure in Vibrational Spectra Analysis. Cientific Drug Delivery Research 1: 13-18.

357. Heidari, Esposito J, Caissutti A (2019) Bufotoxin Time-Resolved Absorption and Resonance FT-IR and Raman Biospectroscopy and Density Functional Theory (DFT) Investigation of Vibronic-Mode Coupling Structure in Vibrational Spectra Analysis Cientific Drug Delivery Research 1: 19-24, 2019.

358. Heidari, Esposito J, Caissutti A (2019) Kainic Acid (Kainite) Time-Resolved Absorption and Resonance FT-IR and Raman Biospectroscopy and Density Functional Theory (DFT) Investigation of Vibronic-Mode Coupling Structure in Vibrational Spectra Analysis. Cientific Journal of Neurology 2: 02-07.

359. Heidari, Esposito J, Caissutti A (2019) Nereistoxin Time-Resolved Absorption and Resonance FT-IR and Raman Biospectroscopy and Density Functional Theory (DFT) Investigation of Vibronic-Mode Coupling Structure in Vibrational Spectra Analysis. Cientific Journal of Neurology 2: 19-24.

360. Heidari, Esposito J, Caissutti A (2019) Spider Toxin and Raventoxin Time-Resolved Absorption and Resonance FT-IR and Raman Biospectroscopy and Density Functional Theory (DFT) Investigation of Vibronic-Mode Coupling Structure in Vibrational Spectra Analysis. Parana Journal of Science and Education 5: 1-28.

361. Heidari, Esposito J, Caissutti A (2019) Ochratoxin A, Ochratoxin B, Ochratoxin C, Ochratoxin $\alpha$ and Ochratoxin TA Time-Resolved Absorption and Resonance FT-IR and Raman Biospectroscopy and Density Functional Theory (DFT) Investigation of Vibronic-Mode Coupling Structure in Vibrational Spectra Analysis. Cientific Drug Delivery Research 2: 03-10.

362. Heidari, Esposito J, Caissutti A (2019) Brevetoxin A and B Time-Resolved Absorption and Resonance FT-IR and Raman Biospectroscopy and Density Functional Theory (DFT) Investigation of Vibronic-Mode Coupling Structure in Vibrational Spectra Analysis. Cientific Drug Delivery Research 2: 11-16.

363. Heidari, Esposito J, Caissutti A (2019) Lyngbyatoxin-a Time-Resolved Absorption and Resonance FT-IR and Raman Biospectroscopy and Density Functional Theory (DFT) Investigation of Vibronic-Mode Coupling Structure in Vibrational Spectra Analysis. Cientific Drug Delivery Research 2: 23-28.

364. Heidari, Esposito J, Caissutti A (2019) Balraechotoxin (BTX) Time-Resolved Absorption and Resonance FT-IR and Raman Biospectroscopy and Density Functional Theory (DFT) Investigation of Vibronic-Mode Coupling Structure in Vibrational Spectra Analysis. Cientific Journal of Neurology 3: 01-05.

365. Heidari, Esposito J, Caissutti A (2019) Hanatoxin Time-Resolved Absorption and Resonance FT-IR and Raman Biospectroscopy and Density Functional Theory (DFT) Investigation of Vibronic-Mode Coupling Structure in Vibrational Spectra Analysis. Int J Pharm Sci Rev Res 57: 21-32.

366. Heidari, Esposito J, Caissutti A (2019) Neurotoxin and Alpha-Neurotoxin TimeResolved Absorption and Resonance FT-IR and Raman Biospectroscopy and Density Functional Theory (DFT) Investigation of Vibronic-Mode Coupling Structure in Vibrational Spectra Analysis. J Biomed Sci \& Res 3: 550-563.

367. Heidari, Esposito J, Caissutti A (2019) Antillatoxin (ATX) Time-Resolved Absorption and Resonance FT-IR and Raman Biospectroscopy and Density Functional Theory (DFT) Investigation of Vibronic-Mode Coupling Structure. American Journal of Optics and Photonics 7: 18-27, 2019.

368. Gobato R, Gobato MRR, Heidari A (2019) Calculation by UFF Method of Frequencies and Vibrational Temperatures of the Unit Cell of the Rhodochrosite Crystal. International Journal of Advanced Chemistry 7: 77-81.

369. Heidari, Esposito J, Caissutti A (2019) Analysis of Vibronic-Mode Coupling Structure in Vibrational Spectra of Fuzeon as a 36 Amino Acid Peptide for HIV Therapy beyond the Multi-Dimensional Franck-Condon Integrals Approximation. International Journal of Advanced Chemistry 7: 82-96.

370. Heidari, Esposito J, Caissutti A (2019) Debromoaplysiatoxin Time-Resolved Absorption and Resonance FT-IR and Raman Biospectroscopy and Density Functional Theory (DFT) Investigation of Vibronic-Mode Coupling Structure in Vibrational Spectra Analysis. Applied Chemistry 2: 17-54. 
Heidari A (2020) Stochastic study of relativistic lutetium nanoparticles moving in a quantum field of synchrotron radiation emission when charged lutetium nanoparticles are accelerated radially in human cancer cells, tissues and tumors treatment

371. Heidari, Esposito J, Caissutti A (2019) Enterotoxin Time-Resolved Absorption and Resonance FT-IR and Raman Biospectroscopy and Density Functional Theory (DFT) Investigation of Vibronic-Mode Coupling Structure in Vibrational Spectra Analysis. JRL J Sci Technol 1: 1-16.

372. Gobato R, Gobato MRR, Heidari A (2019) Rhodochrosite Optical Indicatrix. Peer Res Nest 1: 1-2.

373. Heidari, Esposito J, Caissutti A (2019) Anthrax Toxin Time-Resolved Absorption and Resonance FT-IR and Raman Biospectroscopy and Density Functional Theory (DFT) Investigation of Vibronic-Mode Coupling Structure in Vibrational Spectra Analysis. Research \& Reviews: Journal of Computational Biology 8: 23-51.

374. Heidari, Esposito J, Caissutti A (2019) Kalkitoxin Time-Resolved Absorption and Resonance FT-IR and Raman Biospectroscopy and Density Functional Theory (DFT) Investigation of Vibronic-Mode Coupling Structure in Vibrational Spectra Analysis. Can J Biomed Res \& Tech 2: 1-21.

375. Heidari, Esposito J, Caissutti A (2019) Neosaxitoxin Time-Resolved Absorption and Resonance FT-IR and Raman Biospectroscopy and Density Functional Theory (DFT) Investigation of Vibronic-Mode Coupling Structure in Vibrational Spectra Analysis. Clin Case Studie Rep 2: 1-14.

376. Heidari, Esposito J, Caissutti A (2019) 6-Methoxy-8-[[6-Methoxy-8-[[6- Methoxy2-Methyl-1-(2-Methylpropyl)-3,4-Dihydro-1H-Isoquinolin-7-yl]Oxy]-2- Methyl1-(2-Methylpropyl)-3,4-Dihydro-1H-Isoquinolin-7-yl]Oxy]-2-Methyl-1-(2Methylpropyl)-3,4-Dihydro-1H-Isoquinolin-7-ol Time-Resolved Absorption and Resonance FT-IR and Raman Biospectroscopy and Density Functional Theory (DFT) Investigation of Vibronic-Mode Coupling Structure in Vibrational Spectra Analysis. Clin Case Studie Rep 2: 1-14.

377. Heidari (2019) Comparison of Synchrotron Radiation and Synchrocyclotron Radiation Performance in Monitoring of Human Cancer Cells, Tissues and Tumors. Clin Case Stud Rep 2: 1-12.

378. Heidari, Esposito J, Caissutti A (2019) Kalkitoxin Time-Resolved Absorption and Resonance FT-IR and Raman Biospectroscopy and Density Functional Theory (DFT) Investigation of Vibronic-Mode Coupling Structure in Vibrational Spectra Analysis. Clin Case Stud Rep 2: 1-14.

379. Heidari, Esposito J, Caissutti A (2019) Diphtheria Toxin Time-Resolved Absorption and Resonance FT-IR and Raman Biospectroscopy and Density Functional Theory (DFT) Investigation of Vibronic-Mode Coupling Structure in Vibrational Spectra Analysis: A Spectroscopic Study on an Anti-Cancer Drug. Clin Case Stud Rep 2: $1-14$

380. Heidari, Esposito J, Caissutti A (2019) Symbiodinolide Time-Resolved Absorption and Resonance FT-IR and Raman Biospectroscopy and Density Functional Theory (DFT) Investigation of Vibronic-Mode Coupling Structure in Vibrational Spectra Analysis. Clin Case Studie Rep 2: 1-14.

381. Heidari, Esposito J, Caissutti A (2019) Saxitoxin Time-Resolved Absorption and Resonance FT-IR and Raman Biospectroscopy and Density Functional Theory Investigation of Vibronic-Mode Coupling Structure in Vibrational Spectra Analysis. Am J Exp Clin Res 6: 364-377.

382. Gobato R, Gobato MRR, Heidari A, Mitra A (2019) Hartree-Fock Methods Analysis Protonated Rhodochrosite Crystal and Potential in the Elimination of Cancer Cells through Synchrotron Radiation. Radiation Science and Technology 5: 27-36.

383. Gobato R, Dosh IKK,Heidari A, Mitra A (2019) Perspectives on the Elimination of Cancer Cells Using Rhodochrosite Crystal Through Synchrotron Radiation, and Absorption the Tumoral and Non-Tumoral Tissues. Arch Biomed Eng \& Biotechnol 3: $1-2$.

384. Gobato R, Gobato MRR, Heidari A (2019) Unrestricted Hartree-Fock Computational Simulation in a Protonated Rhodochrosite Crystal. Phys Astron Int J 3: 220-228.

385. Heidari, Schmitt K, Henderson M (2019) Perspectives on Sub-Nanometer Level of Electronic Structure of the Synchrotron with Mendelevium Nanoparticles for Elimination of Human Cancer Cells, Tissues and Tumors Treatment Using Mathematica 12.0. Journal of Energy Conservation 1: 46-73.

386. Heidari, Schmitt K, Henderson M, Besana E (2019) Simulation of Interaction of Synchrotron Radiation Emission as a Function of the Beam Energy and Bohrium Nanoparticles Using 3D Finite Element Method (FEM) as an Optothermal Human Cancer Cells, Tissues and Tumors Treatment. Current Research in Biochemistry and Molecular Biology 1: 17-44.

387. Heidari, Schmitt K, Henderson M, Besana E (2019) Investigation of interaction between synchrotron radiation and thulium nanoparticles for human cancer cells, tissues and tumors treatment. European Journal of Scientific Exploration 2: 1-8.
388. Heidari, Schmitt K, Henderson M, Besana E (2020) the effectiveness of the treatmen human cancer cells, tissues and tumors using darmstadtium nanoparticles and synchrotron radiation. International Journal of Advanced Engineering and Science 9: 39 .

389. Heidari, Schmitt K, Henderson M, Besana E (2019) Using 3D Finite Elemen Method (FEM) as an optothermal human cancer cells, tissues and tumors treatment in simulation of interaction of synchrotron radiation emission as a function of the beam energy and uranium nanoparticles. Nano Prog 1: 1-6.

390. Heidari, Schmitt K, Henderson M, Besana E (2019) A New Approach to Interaction between Beam Energy and Erbium Nanoparticles. Saudi J Biomed Res 4: 372-396.

391. Heidari, Schmitt K, Henderson M, Besana E (2019) Consideration of Energy Functions and Wave Functions of the Synchrotron Radiation and Samarium Nanoparticles Interaction During Human Cancer Cells, Tissues and Tumors Treatment Process. Sci Int (Lahore) 31: 885-908.

392. Heidari, Schmitt K, Henderson M, Besana E (2019) An outlook on optothermal human cancer cells, tissues and tumors treatment using lanthanum nanoparticles under synchrotron radiation. Journal of Materials Physics and Chemistry 7: 29-45.

393. Heidari, Schmitt K, Henderson M, Besana E (2019) Effectiveness of einsteinium nanoparticles in optothermal human cancer cells, tissues and tumors treatment under synchrotron radiation. Journal of Analytical Oncology 8: 43-62.

394. Heidari, Schmitt K, Henderson M, Besana E (2019) Study of Relation between Synchrotron Radiation and Dubnium Nanoparticles in Human Cancer Cells, Tissues and Tumors Treatment Process. Int Res J Applied Sci 1: 1-20.

395. Heidari, Schmitt K, Henderson M, Besana E (2019) A Novel Prospect on Interaction of Synchrotron Radiation Emission and Europium Nanoparticles for Human Cance Cells, Tissues and Tumors Treatment. European Modern Studies Journal 3: 11-24.

396. Heidari, Schmitt K, Henderson M, Besana E (2019) Advantages, Effectiveness and Efficiency of Using Neodymium Nanoparticles by 3D Finite Element Method (FEM) as an Optothermal Human Cancer Cells, Tissues and Tumors Treatment under Synchrotron Radiation. International Journal of Advanced Chemistry 7: 119-135.

397. Heidari, Schmitt K, Henderson M, Besana E (2019) Role and Applications of Promethium Nanoparticles in Human Cancer Cells, Tissues and Tumors Treatment. Scientific Modelling and Research 4: 8-14.

398. Heidari, Esposito J, Caissutti A (2019) Maitotoxin time-resolved absorption and resonance ft-ir and raman biospectroscopy and Density Functional Theory (DFT) investigation of vibronic-mode coupling structure in vibrational spectra analysis: a spectroscopic study on an anti-cancer drug. Glob Imaging Insights 4: 1-13.

399. Heidari, Esposito J, Caissutti A (2019) Biotoxin time-resolved absorption and resonance FT-IR and raman biospectroscopy and density functional theory (DFT) investigation of vibronic-mode coupling structure in vibrational spectra analysis. Glob Imaging Insights 4: 1-14.

400. Heidari, Esposito J, Caissutti A (2019) Time-Resolved Resonance FT-IR and raman spectroscopy and density functional theory investigation of vibronic-mode coupling structure in vibrational spectra of nanopolypeptide macromolecule beyond the multidimensional franck-condon integrals approximation and density matrix method. Glob Imaging Insights 4: 1-14

401. Heidari, Esposito J, Caissutti A (2019) Cholera Toxin Time-Resolved Absorption and Resonance FT-IR and Raman Biospectroscopy and Density Functional Theory (DFT) Investigation of Vibronic-Mode Coupling Structure in Vibrational Spectra Analysis. Glob Imaging Insights 4: 1-14.

402. Heidari, Esposito J, Caissutti A (2019) Nodularin time-resolved absorption and resonance FT-IR and raman biospectroscopy and density functional theory (DFT) investigation of vibronic-mode coupling structure in vibrational spectra analysis. Glob Imaging Insights 4: 1-14.

403. Heidari, Esposito J, Caissutti A (2019) Cangitoxin time-resolved absorption and resonance FT-IR and raman biospectroscopy and density functional theory (DFT) investigation of vibronic-mode coupling structure in vibrational spectra analysis. Glob Imaging Insights 4: 1-13, 2019.

404. Heidari, Esposito J, Caissutti A (2019) Ciguatoxin time-resolved absorption and resonance FT-IR and raman biospectroscopy and density functional theory (DFT) investigation of vibronic-mode coupling structure in vibrational spectra analysis. Glob Imaging Insights 4: 1-14.

405. Heidari, Esposito J, Caissutti A (2019) Brevetoxin (a) and (b) time-resolved absorption and resonance ft-ir and raman biospectroscopy and density functional theory (DFT) investigation of vibronic-mode coupling structure in vibrational spectra analysis: a spectroscopic study on an ANTI-HIV drug. Cientific Drug Delivery Research 1: 11-16. 
Heidari A (2020) Stochastic study of relativistic lutetium nanoparticles moving in a quantum field of synchrotron radiation emission when charged lutetium nanoparticles are accelerated radially in human cancer cells, tissues and tumors treatment

406. Heidari, Esposito J, Caissutti A (2019) Cobrotoxin time-resolved absorption and resonance FT-IR and raman biospectroscopy and density functional theory (DFT) investigation of vibronic-mode coupling structure in vibrational spectra analysis. Trends in Res 3: 1-13, 2019.

407. Heidari, Esposito J, Caissutti A (2019) Cylindrospermopsin time-resolved absorption and resonance FT-IR and raman biospectroscopy and density functional theory (DFT) investigation of vibronic-mode coupling structure in vibrational spectra analysis. Trends in Res 3: 1-14.

408. Heidari, Esposito J, Caissutti A (2019) Anthrax toxin time-resolved absorption and resonance FT-IR and raman biospectroscopy and density functional theory (DFT) investigation of vibronic-mode coupling structure in vibrational spectra analysis. Trends in Res 3: 1-14.

409. Heidari, Schmitt K, Henderson M, Besana E (2019) Investigation of moscovium nanoparticles as anti-cancer nano drugs for human cancer cells, tissues and tumors treatment. Elixir Appl Chem 137: 53943-53963.
410. Heidari, Schmitt K, Henderson M, Besana E (2019) Study of function of the beam energy and holmium nanoparticles using 3D Finite Element Method (FEM) as an optothermal human cancer cells, tissues and tumors treatment. European Journal of Advances in Engineering and Technology 6: 34-62.

411. Heidari, Schmitt K, Henderson M, Besana E (2019) Human cancer cells, tissues and tumors treatment using dysprosium nanoparticles. Asian J Mat Chem 4: 47-51.

412. Heidari, Schmitt K, Henderson M, Besana E (2019) Simulation of interaction of synchrotron radiation emission as a function of the beam energy and plutonium nanoparticles using $3 \mathrm{~d}$ finite element method (FEM) as an optothermal human cancer cells, tissues and tumors treatment. J Cancer Research and Cellular Therapeutics 2: 1-19.

413. Heidari, Schmitt K, Henderson M, Besana E (2019) Study of gadolinium nanoparticles delivery effect on human cancer cells, tissues and tumors treatment under synchrotron radiation. Applied Chemistry 2: 55-97.

414. Heidari, Schmitt K, Henderson M, Besana E, Gobato R (2020) Pros and cons of livermorium nanoparticles for human cancer cells, tissues and tumors treatment under synchrotron radiation using mathematica 12.0. Parana Journal of Science and Education 11.

Copyright: (C2020 Heidari A. This is an open-access article distributed under the terms of the Creative Commons Attribution License, which permits unrestricted use, distribution, and reproduction in any medium, provided the original author and source are credited. 